\title{
Title: History of agriculture and intensity of warfare shaped the evolution of large-scale human societies in Afro-Eurasia
}

Authors: Thomas E. Currie ${ }^{1 *}$, Peter Turchin ${ }^{2,3}$, Sergey Gavrilets ${ }^{4,5,6}$

\author{
Affiliations: \\ ${ }^{1}$ Human Biological and Cultural Evolution Group, Centre for Ecology \& Conservation, \\ Department of Biosciences, University of Exeter, Penryn Campus. UK \\ ${ }^{2}$ Complexity Science Hub Vienna, Austria \\ ${ }^{3}$ Department of Ecology \& Evolution, University of Connecticut. USA \\ ${ }^{4}$ Department of Mathematics, University of Tennessee, Knoxville \\ ${ }^{5}$ National Institute for Mathematical and Biological Synthesis, University of Tennessee, \\ Knoxville \\ ${ }^{6}$ Center for the Dynamics of Social Complexity, University of Tennessee, Knoxville \\ * To whom correspondence should be addressed: T.Currie@exeter.ac.uk
}

\begin{abstract}
Understanding why large, complex human societies have emerged and persisted more readily in certain regions of the world than others is an issue of long-standing debate. Here we systematically test a range of hypotheses involving the socio-ecological factors that may ultimately promote or inhibit the formation of large, complex human societies. We employ spatially explicit statistical analyses using data on the geographical and temporal distribution of the largest human groups over a 3000 year period of history. The results support the predictions of two complementary hypotheses indicating that large-scale societies developed more commonly in regions where i) agriculture has been practiced for longer (thus providing more time for the norms \& institutions that facilitate large-scale organization to emerge), and ii) warfare was more intense (thus creating a stronger selection pressure for societies to scale up). We found no support for the influential idea that large-scale societies were more common in those regions naturally endowed with a higher potential for productive agriculture. Our study highlights how modern cultural evolutionary theory can be used to organize and synthesize alternative hypotheses and shed light on the ways ecological and social processes have interacted to shape the complex social world we live in today.
\end{abstract}

\section{Significance}


Understanding why large, complex human societies have emerged and persisted more readily in some parts of the world has long been debated. Our statistical analyses of global historical data over a 3000-year period indicated that large-scale societies developed more commonly in regions where i) agriculture has been practiced for longer (thus providing more time for effective solutions to collective action problems to emerge), and ii) warfare was more intense (thus creating a stronger pressure for societies to become larger). Our study highlights how systematic analyses of human cultural evolution can shed light on the ways ecological and social processes have interacted to shape the complex social world we live in today.

/body

The size and complexity of modern human societies is on a scale unmatched in other species. Yet for much of our evolution humans lived in small-scale, internally undifferentiated groups, and it is only in the last several thousand years that larger-scale societies with more complex forms of organization began to develop resulting in what we can label "macro-states" or "empires" involving millions of individuals. Anecdotal (1) and empirical (2) research indicates that historically the largest human societies tended to be situated in a relatively narrow band of the Afro-Eurasian landmass, stretching from Western and Central Europe and the Mediterranean in the West, through to China in the East (Fig 1). Understanding how and why humans are able to form functioning societies on such a scale, and why large, complex societies have tended to form more readily in certain places are questions of long-standing interest across a range of disciplines (3-5). The strong geographic patterns noted above suggest that ecology may play an important role yet a number of other factors have been proposed to be important in driving the evolution of social complexity such as the development and productivity of agriculture $(1,6)$, information processing (7), warfare (2), the geography of continental land masses (1), technology (7), and religion (8). However, there have been relatively few empirical tests of these competing ideas within a common theoretical framework. Here we employ modern cultural evolutionary theory to systematically develop and empirically test a range of alternative hypotheses involving the socioecological factors that may ultimately promote or inhibit the formation of large, complex human societies.

\section{Deriving Cultural Evolutionary hypotheses}

Cultural evolutionary theory (CET) is a conceptual framework concerned with understanding how and why socio-cultural traits emerge and spread (9-11). In CET cultural traits are seen to exhibit variation that is inherited from one individual or group to another, and when there is competition then selection and adaptation can occur; mirroring the key processes of biological evolution (12). For groups to remain politically unified as they expand their territory, either through the physical movement of people, or the joining together or annexation of other groups, cultural norms and institutions must be developed that structure social interactions and enable social cohesion (13-16). For example, establishment of formal leaders with the authority to 
punish free-riders can solve collective action problems (17), whilst more hierarchical organization and specialized, bureaucratic forms of political organization can improve coordination over larger distances (18-20). While a large number of processes may be involved in the evolution of large-scale societies, our focus here is on factors that have systematically affected the geographic and temporal distribution of such groups. From a CET perspective, the variation seen in the occurrence of large-scale societies, could be due to differences in different parts of the world relating to i) the benefits and costs of large-scale organization (selection), ii) the generation of different socio-cultural traits involved in large-scale organization (variation), iii) the transmission of these traits across time and space (inheritance). Here we develop specific hypotheses about the factors in the real world relating to these processes of selection, variation, and inheritance.

In humans, competition between groups is potentially a strong selective force. While warfare has probably occurred throughout history, the intensity of between-group conflict has varied across space and time. A major historically-attested factor intensifying warfare was the development of horse-based military technologies such as chariots and cavalry (2). These first developed in the pastoralist societies of the Eurasian steppe and enabled such groups to raid settled agricultural societies in regions neighboring the steppe, sometimes inflicting severe casualties (21). It is hypothesized that pressure from the steppe selected for the unification and scaling-up of agricultural societies into larger groups to more effectively counteract these incursions. This in turn would select for greater size in pastoralist communities, and also other neighboring agricultural groups who were now relatively smaller and at a competitive disadvantage with their neighbours. This effect would be amplified by the diffusion of such military technology from the steppe. Under this hypothesis we would predict that there is relationship between the occurrence of large-scale societies and distance from the Eurasian steppe (relating to the presence of intensive forms of horse-based warfare), with large-scale societies occurring more frequently nearer the steppe (the "steppe warfare" hypothesis).

A number of factors may affect the probability of developing the kinds of norms and institutions that underpin larger scale societies (i.e. the generation of variation may be greater in some regions than others). While the rate of cultural evolution is generally faster than biological evolution, the development of social norms \& institutions for collective action is not straightforward and may require long periods of cultural experimentation $(22,23)$. Furthermore, norms and institutions may need to accumulate over generations and build on preceding innovations $(24,25)$. Differences in the time that has been available to societies to develop the institutions that underpin stable large-scale organization may therefore play an important role in explaining the distribution of such societies. Related to this, agriculture is often cited as being a necessary condition for large, centralized societies due as it enables societies to develop and finance institutions of coordination and control involving political specialists (leaders, bureaucrats, priests etc.) who do not produce their own food but are supported by the rest of the population due to the productive nature of the resource base $(26,27)$. Both the duration $(1,7)$ and productivity $(6,26)$ of agriculture have featured prominently in debates in the evolution of sociopolitical complexity. For this paper we therefore predict that large scale societies would occur more in places where agriculture has been practiced for longer (the "duration of agriculture" hypothesis), or where the productivity of agriculture is higher (the "agricultural productivity" hypothesis). For the second of these ideas we focus on the hypothesis that some 
regions may have had more favourable ecological conditions and examine potential agricultural productivity rather than achieved productivity, representing a kind of productivity endowment.

The above hypotheses capture the roles of selection and variation (which is inherited and accumulated over time) in potentially affecting the spatio-temporal distribution of large-scale societies. However these processes can also interact - in order for selection to occur variation in cultural traits needs to be generated. We therefore also assess whether the effect of selection is stronger in regions that have had longer to develop (i.e. we predict a positive interaction between proximity to the steppe and duration of agriculture).

Finally, we also control for two factors in assessing support for the above ideas. We assess whether more rugged regions are more difficult to be conquered and brought under control by an outside force (the "terrain ruggedness" hypothesis)(28). We also control for the possibility that the spread of large-scale societies and their norms \& institutions was not due to any of the processes outlined above but may simply have been contingent on where the first such societies initially arose (the "first empires" hypothesis) - warfare may have been more intense initially near these regions leading to scaling up of societies in neighbouring regions, and/or technological or social innovations may have diffused out from these regions.

\section{Spatially-explicit statistical analyses and incorporation of uncertainty in historical data}

In order to test the predictions of these hypotheses we statistically assess how well these factors explain real-world data on the historical and geographical distribution of large-scale societies. We examine data on the spatial and temporal distribution of large states and empires in Afro-Eurasia from the period $1500 \mathrm{BCE}-1500 \mathrm{CE}$ (2). Our data consist of maps of the extent of politically unified states and empires ("polities") taken from historical atlases and other sources and sampled at 100-year intervals. In order to conduct statistical analyses we created a grid, and for each time step we assessed whether a grid cell was occupied by a polity greater than $100,000 \mathrm{~km}^{2}$. We confine our analyses to those regions of the world for which agriculture was practiced at 1500CE. Data from different time slices are combined to assess how frequently different cells have been occupied by polities over the entire 3000 year time span which is our main dependent variable "imperial density" (Fig 2). In order to test the different hypotheses outlined above we used historical and ecological sources of information to create the following predictor variables: (i) Distance from the Eurasian steppe (as a proxy for the intensity of warfare), (ii) time since development of agriculture, (iv) potential agricultural productivity, (iii) terrain ruggedness, (iv) distance from the first empires present at $1500 \mathrm{BCE}$.

To assess whether our results are due to assumptions made in the construction of predictor variables we created two versions of the distance-from-steppe variable (a more inclusive classification (Distance from Steppe (Max)), and a more restrictive (Distance from Steppe (Min)), and three versions of the duration-of-agriculture variable (a "best" estimate, and "minimum" and "maximum" estimates). This enables to assess whether our results are robust to the kind of uncertainty that is necessarily present when conducting these kinds of analyses. 


\begin{tabular}{|c|c|c|c|c|c|c|c|c|c|}
\hline & 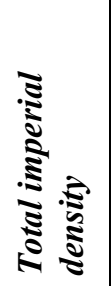 & 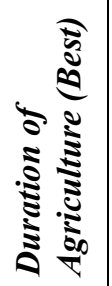 & 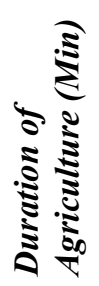 & 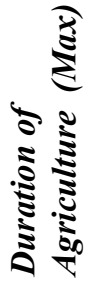 & 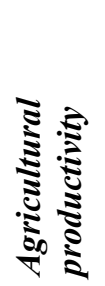 & 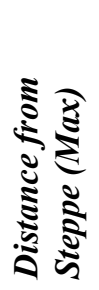 & 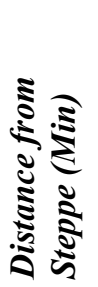 & 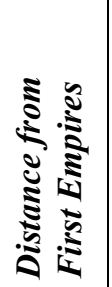 & 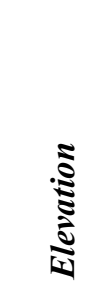 \\
\hline Total imperial density & & -0.56 & -0.61 & -0.53 & 0.01 & -0.72 & -0.72 & -0.60 & 0.20 \\
\hline Duration of Agriculture (Best) & -0.62 & & 0.99 & 0.99 & 0.07 & 0.44 & 0.44 & 0.55 & -0.13 \\
\hline Duration of Agriculture (Min) & -0.66 & 0.99 & & 0.98 & 0.08 & 0.49 & 0.48 & 0.56 & -0.15 \\
\hline Duration of Agriculture (Max) & -0.59 & 0.99 & 0.97 & & 0.05 & 0.40 & 0.40 & 0.52 & -0.12 \\
\hline Agricultural productivity & 0.01 & 0.07 & 0.06 & 0.06 & & 0.10 & 0.07 & 0.08 & -0.11 \\
\hline Distance from Steppe (Max) & -0.62 & 0.47 & 0.51 & 0.42 & 0.08 & & 0.96 & 0.77 & -0.10 \\
\hline Distance from Steppe (Min) & -0.62 & 0.47 & 0.52 & 0.43 & 0.07 & 0.96 & & 0.69 & -0.10 \\
\hline Distance from First Empires & -0.61 & 0.52 & 0.53 & 0.49 & 0.06 & 0.82 & 0.73 & & -0.17 \\
\hline Elevation & 0.19 & -0.15 & -0.18 & -0.13 & -0.11 & -0.10 & -0.11 & -0.13 & \\
\hline
\end{tabular}

Table 1. Correlation matrix of imperial density and the predictor variables tested in this paper (lower left: Pearson correlation coefficients, upper right: Spearman rank correlations). Different measures of duration of agriculture and distance for the Steppe are given to capture the uncertainty in these variables. Imperial density is generally greater closer to the steppe and with increasing duration of agriculture. There is not a strong relationships between imperial density and potential productivity. There is a strong relationship between imperial density and the control variable of distance from first empires, but the relationship with elevation (terrain ruggedness) is fairly weak and in the opposite direction to that predicted. There are also substantial positive relationship between the measures of duration of agriculture, the measures of distance from the steppe, and the distance from first empires.

Correlational analyses indicates that distance from the steppe, duration of agriculture, and distance from first empire all show patterns in line with the predictions of the relevant hypotheses (Table 1). However, potential agricultural productivity does not appear to predict imperial density well; estimated productivity is high in many places where empires did not tend to form for example. Ruggedness of terrain also does not show a strong relationship with imperial density and indicates slightly higher imperial density in more rugged areas (which is in the opposite direction to that predicted). These analyses also reveal substantial correlations between the main predictor variables. This highlights the need to assess these hypotheses within the same model rather than examining purely independently. 
To systematically test between the hypotheses, we conducted statistical analyses using a generalized least squares (GLS) framework, which allows incorporation of the spatial structure and autocorrelations contained in the data (see Supplementary Information). Given the large dataset, the number of models that needed to be analysed, and the memory-intensive nature of the GLS approach we ran the analyses on 20 random sub-samples of the data and made inferences based on results from across all the samples. We specified a variety of different models reflecting the different hypotheses outlined above and different combinations of predictors in order to assess the relative importance of different factors using model-selection techniques (29). Models contain the main effects of the different predictors as well as the interaction between distance from the steppe and duration of agriculture where appropriate.

Comparing the fits of different models (Table 2) involving different combinations of the main predictor variables and ruggedness of terrain shows that the best-fitting models include the variables duration of agriculture, potential agricultural productivity, terrain ruggedness, and distance from the steppe. The interaction between duration of agriculture and distance from the steppe is also included in the best-supported models. The standardized parameter estimates $(\beta)$ indicate the strength of the association between our predictor variables and imperial density. The results (Table 2) indicate that duration of agriculture and distance from the steppe are the strongest predictors of imperial density, with the interaction term also being important. The parameter estimates for ruggedness and productivity are indistinguishable from zero. Including distance from first empires substantially increases the fit of the best models and this variable has the strongest standardized parameter estimate $(\beta=0.40)$. The variables duration of agriculture $(\beta=0.21)$ and the interaction term $(\beta=0.14)$ show very small decreases in their parameter estimates, while distance from the steppe is more heavily affected $(\beta=0.11)$ but still remains significant. Overall, the best fitting model explains more than $50 \%$ of the variation in imperial density in this dataset (Fig 3).

\begin{tabular}{|c|c|c|c|c|c|c|c|}
\hline & $\begin{array}{c}\text { Duration of } \\
\text { agriculture }\end{array}$ & $\begin{array}{r}\text { Distance } \\
\text { from Steppe }\end{array}$ & $\begin{array}{l}\text { Agricultural } \\
\text { productivity }\end{array}$ & Elevation & $\begin{array}{c}\text { Steppe }^{*} \\
\text { Agriculture }\end{array}$ & $\begin{array}{r}\text { mean } \\
\text { rank }\end{array}$ & $\begin{array}{l}\text { mean } \\
\Delta A I C\end{array}$ \\
\hline \multirow{9}{*}{ 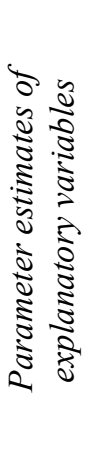 } & 0.25 & 0.45 & & & 0.16 & 1.35 & 0.73 \\
\hline & 0.25 & 0.45 & $<0.01$ & 0.01 & 0.16 & 1.7 & 1.57 \\
\hline & 0.34 & 0.36 & & & & 3.3 & 9.32 \\
\hline & 0.34 & 0.36 & $<0.01$ & 0.01 & & 3.65 & 10.11 \\
\hline & 0.38 & & & & & 5.05 & 27.33 \\
\hline & & 0.47 & & & & 5.95 & 39.80 \\
\hline & & & & & & 7.5 & 62.56 \\
\hline & & & $<0.01$ & & & 8.15 & 62.94 \\
\hline & & & & 0.01 & & 8.35 & 63.01 \\
\hline
\end{tabular}

Table 2. GLS spatial models with different predictor variables ranked according to how well they fit the data based on mean AIC values from across the 20 sub-samples of data. Standardized coefficients $(\beta)$ are presented to indicate the relative strength of each predictor. The best-fitting model contains duration of agriculture and distance from the steppe, and the interaction between these two variables. Only one other model falls within 2 mean AIC units of the best fitting-model (as indicated in bold) and this also includes small effects of agricultural productivity and elevation. 


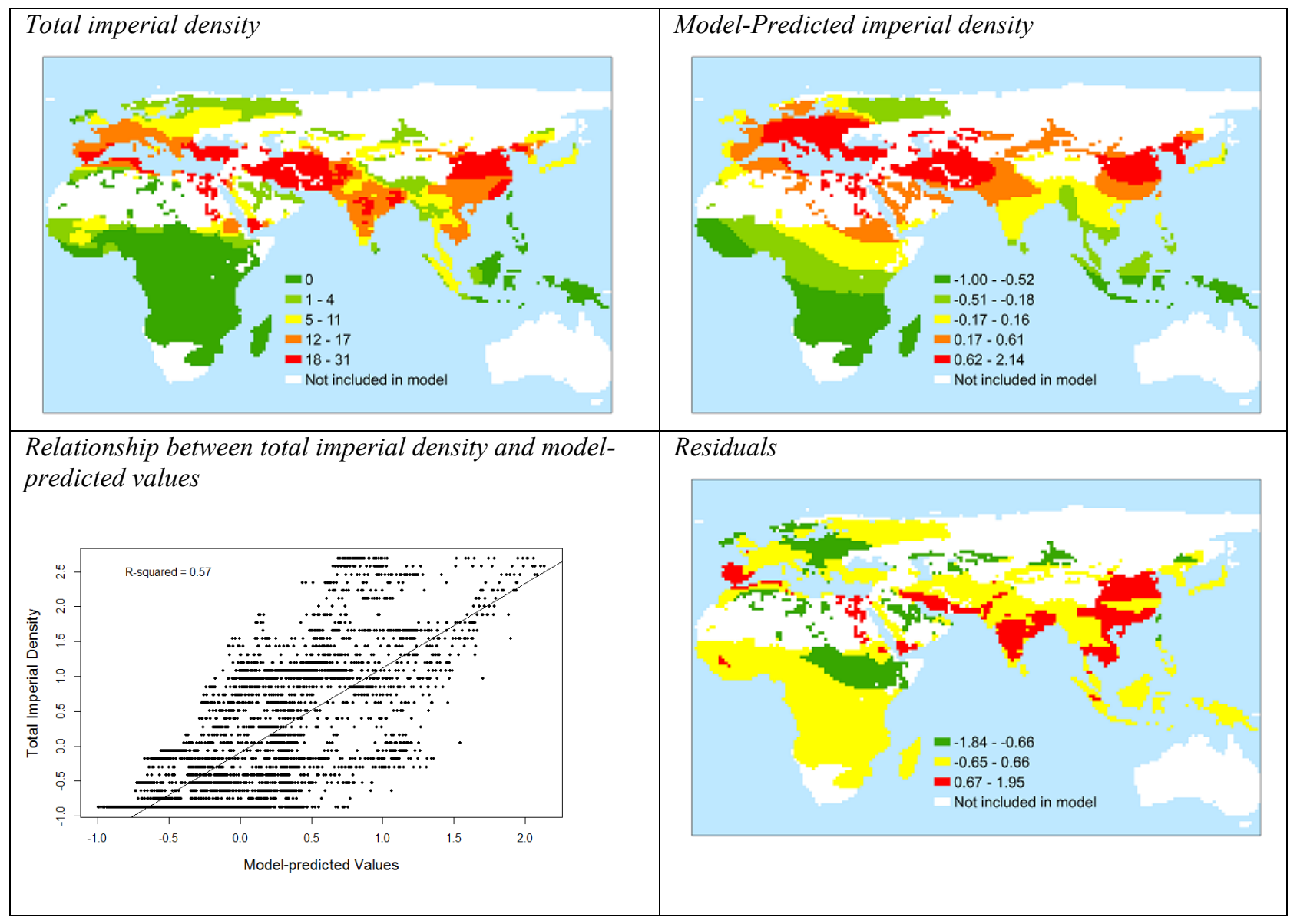

Figure 1. Distribution of imperial density (upper left) compared to distribution predicted by spatial GLS model (upper right)(values are divided into 5 quantiles). Comparison of observed imperial density and predicted values from GLS model (straight line is the regression line)(bottom left). The residuals (lower right) from this relationship indicate where the model predicts the real data reasonably well (within 1 standard deviation, yellow), or where it over-(green) or under-(red) estimates the observed imperial density. 
We also assessed whether the predictive strength of different factors varies through time. Figure 4 shows how well the variables predict imperial density over a sliding 1000 -year window, i.e. we begin at $500 \mathrm{BCE}$ and run statistical models that examine imperial density from 1500BCE500BCE, we then move to $400 \mathrm{BCE}$ and examine imperial density over the period 1400BCE400BCE, and so on until 1500AD. In all analyses the distance from the steppe shows a substantial uptick towards the end of the time period considered. This could reflect the increasing intensity of warfare as time went on and the incursions into Europe by groups such as the Mongols. It is also important to note that this may also be due to the spread of European large state societies into Eastern Europe up to the steppe and the Ural mountains during these later periods. Duration of agriculture is a good predictor of imperial density and shows a slight increase in predictive strength before slightly decreasing. This reflects the fact that initially the spread of empires broadly follows the routes taken in the previous spread of agriculture, but then in later periods discrepancies begin to emerge (see Supplementary discussion). Interestingly the interaction term between duration of agriculture and distance from steppe decreases steadily over time. The potential productivity of agriculture and elevation are poor predictors through all time periods. Further analyses (see SI) reveal that the effect of distance from the first empire declines steadily over time. This suggests that in early time periods the location of these early empires may have been an important factor increasing the probability of large-scale societies inhabiting surrounding areas. However, this did not have a strong deterministic effect on the development of such societies as time went on and other historical or ecological processes increased in importance.

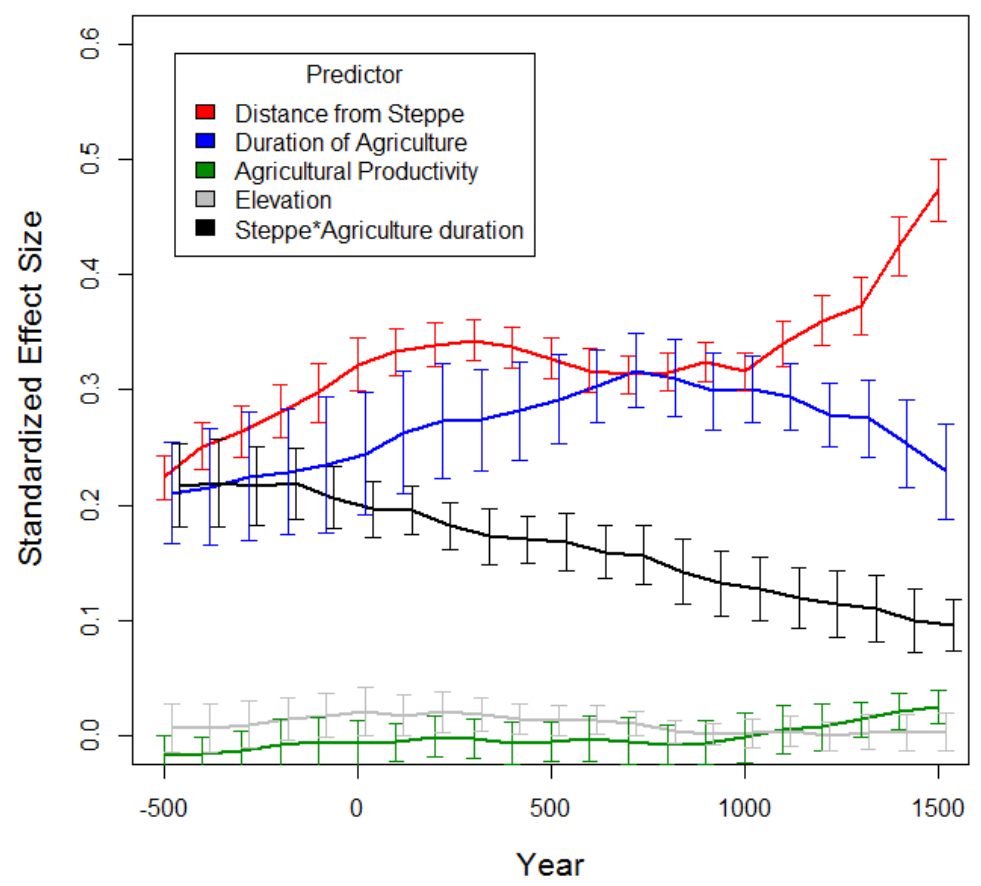


Figure 2. Variation in predictive strength of variables from the best-fitting model over the sampled period. Graphs show the standardized parameter estimates of variables (+/- SD) as predictors of imperial density over the 1000 years prior to the date indicated.

\section{Discussion}

In this paper we have tested a number of influential hypotheses about the evolution of the large, complex human societies. Overall, the results show strongest support for the duration of agriculture hypothesis and the steppe warfare intensity hypothesis. These two ideas are complementary and we find support for an interaction between our measures of duration of agriculture and intensity of warfare, indicating that selection for large-scale societies has had more chance to act when the required variation in norms \& institutions has been generated. Importantly these effects remain significant even when distance from first empires is introduced as a control variable. The fact that the distance from first empires variables is to some degree auto-correlated with the imperial density variable makes this quite a conservative test of the other hypotheses. This suggests duration of agriculture and intensity of warfare really are explaining variation that would not be predicted if the patterns we see simply are due to the historically contingent locations of the initial areas of high social complexity. It is also not surprising that the steppe warfare hypothesis is more strongly affected by the inclusion of distance from first empires as both hypotheses involve similar processes (intensity of warfare, and diffusion of innovations), albeit for different reasons and due to different initial starting conditions. The fact that duration of agriculture and the interaction effect are less affected also lends support to the idea that they represent different processes. The study is also revealing in indicating the hypotheses that are poor explanations of the data. Both the productivity endowment hypothesis and the terrain ruggedness hypothesis are not supported by our analyses.

Our confidence in these results is supported by the fact that different measures of the variables of interest produce broadly similar results (see Table $1 \&$ supplementary analyses). The causal interpretation of our analyses is also supported by the fact that the variables chosen are exogenous in that their variation is not dependent on or shaped by the presence of complex societies. Agriculture was first practiced in societies at a scale much smaller than those that are the focus of our analyses in this paper, and in all cases in this dataset agriculture was present in regions before large-scale societies are recorded as being present. We have used distance from the steppe as a proxy for warfare intensity rather than actual measures of warfare intensity partly because warfare may itself be a function of social scale and related increases in warfare technology. Similarly focusing on potential agricultural productivity (rather than actual or achieved productivity) avoids the problem that larger societies may develop more intense forms of agriculture (see below).

Our results indicate the importance of ecology and geography in shaping the evolution of complex societies. The hypotheses relating to the two best predictors both involve the emergence of certain practices that were more likely to occur in certain places rather than others (i.e. the domestication of crops in suitable environments, and the domestication of horses and use in warfare in the Eurasian steppe). These practices then subsequently spread geographically either through population movements or adoption by neighbouring groups. As the lack of support for the productivity endowment hypothesis also suggests, these results do not point to a strong form of environmental determinism (in which external environmental factors dictate that human 
history would unfold unerringly in a certain way)(30) but rather stress the importance of the ways in which humans interact and shape their social and natural environments. Although we find no support for the agricultural endowment hypothesis, it should be noted that our analyses do incorporate the assumption that some non-zero degree of agricultural productivity is essential. What are our analyses indicate however is that beyond this baseline regions that had the potential to be more productive are no more likely to have been occupied by large-scale societies than regions of lower productive potential. It is important to note, achieved, rather than potential, agricultural production is likely to be an important factor in that it supports and enables complex societies to function. Achieved production is a function not just of ecological endowment but also the technologies that societies develop, which may be developed in response to increasing population pressure and may be facilitated by more complex forms of organization. In the future, comparative time series data on changing agricultural practices and technologies will enable us to further assess the relationship between agricultural productivity and the evolution of complex societies (31), taking into account the potential reciprocal causal pathways involving these factors and changes in productivity over time due to historical climate change.

Factors and processes other than those examined in this study may also be important in determining the geographic and temporal distribution of larger-scale societies. Selection also requires that cultural traits and innovations persist and be inherited from one generation to the next. The ability of cultural traits to be transmitted between societies also means that societies may not have to develop solutions to collective action problems independently but can borrow such innovations from other societies. Traits may be more likely to be transmitted between societies that are similar ecologically and culturally. Furthermore, just as biological species can disperse most easily into regions to which they are genetically or behaviourally pre-adapted (32), human groups may find it easier to spread and expand their control over regions that are similar ecologically or culturally as the institutions they possess are suited to such conditions. Our bestfitting statistical model over-predicts the occurrence of large-scale societies in sub-Saharan Africa and parts of island southeast Asia and New Guinea (Fig 3), which indicates it is not capturing some important process or interaction with another factor. The kind of ecological or cultural barriers discussed above may be one potential explanation as to why this is the case. More generally, it has been argued that as Eurasia extends predominantly along lines of latitude, where ecological conditions are more similar, the traits involved in creating large-scale societies and the societies themselves could spread more easily here as compared to elsewhere $(1,33)$. It has also been proposed that new institutions may also be more effective when they are adopted by or imposed on societies that share a common cultural history, and therefore possess more similar cultural traits and institutions $(24,34,35)$. In supplementary analyses (see SI) we have conducted some initial exploratory tests of these ideas, but we do find support for the predictions of these hypotheses. However, further tests are required before we can be confident about rejecting such processes as important in shaping the distribution of large-scale societies. Another issue is to what extent the processes identified in this study have also been important in the Americas and in later time periods. In both these cases, the particular technological factor of horse-based warfare was not present (the Americas) or reduced in importance (i.e. due to the subsequent development of firearms, and increasing importance of naval warfare in Eurasia). In these cases it will be important to identify other variables that may be better proxies for selectionbased hypotheses. It also worth noting that regions where some large-scale states such as the Incas and Aztecs did emerge are also known to be important early centres of plant domestication 
(36). Therefore, the duration of agriculture of hypothesis may also be relevant in this part of the world. Such tests would provide "natural experiments" in which to assess the generality of these ideas.

In contrast to this study, much previous historically-informed research has focused on the particular cultural traits, social features or even individual characteristics of leaders that may have led to the success of certain societies over others $(37,38)$. Here our focus is on hypotheses that make tractable predictions about geographic patterns of variation, yet other explanations for the origin and maintenance of complex societies also possible (see Supplementary discussion). For example, we assessed the idea that the increased size of human society benefits the majority of the population, however, it is important to recognize that complex societies exhibit high degrees of inequality, with elites potentially benefitting more than the masses from such forms of organization (39). Future work will examine the different costs and benefits for individuals within societies and the changing levels of inequality over human history and the social and ecological conditions under which this occurs.

More generally the study also highlights the importance of setting out and testing alternative hypotheses about human cultural evolution. The kind of cultural evolutionary approach taken in this paper enables us to integrate insights and findings from different disciplines and to develop hypotheses with a clear understanding about how those ideas might fit together. This provides a framework to understand whether hypotheses are competing or complementary, and allows us to quantitatively assess how well they explain the data and whether some ideas can be rejected. In doing so we can develop a better understanding of the historical and ecological processes that have shaped the world of large-complex societies that we live in today.

\section{Methods}

\section{Data}

A spatial explicit dataset was created in the Geographic Information System ArcGIS v.10. Data were organized in grid cells under an equal-area projection so as to maintain a constant cell size of $2500 \mathrm{~km}^{2}$ (approximately $50 \mathrm{~km}$ by $50 \mathrm{~km}$ ). Maps showing the geographical distribution of the data are shown in Figs S1 and S2. Analyses were conducted using cells in which agriculture was practiced by $1500 \mathrm{CE}$, and cells in which potential agricultural production was possible.

Imperial density: Data on the global and historical distribution of large-scale societies $\left(>100,000 \mathrm{~km}^{2}\right)$ were based on historical atlases and other sources (see SI). Polygons of empires at each time step were created and areas were calculated under an equal-area projection. Polygons $<100,000 \mathrm{~km}^{2}$ were not included in the final dataset.

Duration of agriculture: An estimate of the time since agriculture was practiced in various parts of the world was taken from a variety of sources reflecting the latest archaeological information (see SI for definitions and literature). For testing this hypothesis we are primarily concerned with 
evidence about when societies began to cultivate food as a major part of their diet (see SI). Data were entered into a GIS as points, and in order to gain full global coverage these data were interpolated using the Spline algorithm, which creates a smooth surface that goes through the input data points. Uncertainty in these dates was incorporated by specifying minimum and maximum dates and creating two additional maps.

Agricultural productivity: The agricultural productivity hypothesis (H3) reflects the natural endowment of conditions conducive to productive agriculture (e.g. climate, available crops, soil) rather than achieved agricultural production that may rely on technological or cultural innovations that raise productivity (cf. (40)). Data on estimated potential crop productivities were taken from the Food and Agriculture Organization of the UN's Global Agro-Ecological Zones (FAO GAEZ) methodology v.3 (41). Different crop types were used in different regions to reflect the kinds of crops that were grown historically. We make the simplifying assumption that overall potential agricultural productivity can be reasonably proxied by the maximum potential yield from the main carbohydrate staple crop. Climatic effects were based on the baseline average climatic conditions from 1961 to 1990. See discussion and SI for evaluation of these assumptions with respect to this paper.

Distance measures: Distance from the Steppe, and distance from the first empires were calculated under equidistant projections. The steppe region was defined according to the WWF terrestrial ecoregions of the world map. The assumptions about what should be classified as the Steppe for the purposes of this study follow (2) but the effects of assuming a more restricted classification are also explored (Table 1, SI). The first empires are defined as those regions that had empires $>100,000 \mathrm{~km}^{2}$ at $1500 \mathrm{BC}$.

Elevation: Elevation data was taken from the GTOPO30 digital elevation model of the world (USGS)(resolution: 30 arc-seconds)(42). The measure of the unevenness of terrain was calculated as the standard deviation of altitude across each grid cell.

\section{Statistical Analyses}

Main analyses were carried out using the nlme (non-linear mixed-effects) package (43) in R (44), using longitude and latitude as random control variables (following (45)). Including the spatial structure of the data in nlme using GLS is extremely memory intensive we therefore ran analyses on random sub-samples of the data each involving 1000 cells. For the main analyses we ran analyses over a number of such samples in order to ensure that results were not dependent on any particular sample (see below). All dependent and predictor variables were scaled in order to produce standardized parameter estimates.

Testing alternative models: In order to test between the alternative hypotheses we specified different statistical models containing different predictors of imperial density. We ran models containing the predictor variables of duration of agriculture, productivity of agriculture, terrain ruggedness, ecological similarity and cultural similarity, and distance from the steppe as main effects. We also assessed to what extent model fit and parameter estimates were affected by including distance from first empires as a variable in these models. We also assessed the impact 
of including interaction terms involving duration of agriculture, productivity of agriculture or the warfare intensity variables (see SI, Table S2). We compared models in a model selection framework (29) based on Akaike Information Criteria (AIC)(46). Each model was run on 20 random samples of 1000 cells to assess variation in the parameter estimates. As likelihoods are not directly comparable across samples we used change in AIC ( $\triangle \mathrm{AIC})$ to guide model comparability across samples.

Model parameters over time: In order to assess if there were any changes in the strength of our different main factors as predictors of imperial density over time we ran analyses over a sliding time frame of 1000 years. In other words we first analyse a model containing duration of agriculture, productivity of agriculture, and distance from the steppe as predictors of imperial density for the period 1500BCE-600BCE. We then analyse the period 1400BCE-500CE etc. Within these time frames we set anywhere to which agriculture had not spread a value of 0 for duration of agriculture, and a value of 0 for productivity of agriculture. To assess the effect of distance from first empire we ran these models again including this variable. Each model was run on 10 random samples of 1000 cells to assess variation in the parameter estimates.

\section{References}

1. J. Diamond, Guns, germs and Steel. (Vintage, London, 1997).

2. P. Turchin, T. E. Currie, E. A. L. Turner, S. Gavrilets, War, space, and the evolution of Old World complex societies. Proceedings of the National Academy of Sciences 110, 16384 (October 8, 2013, 2013).

3. K. Flannery, J. Marcus, The Creation of Inequality: how our prehistoric ancestors set the stage for monarchy, slavery, and empire. (Harvard University Press, 2012).

4. R. L. Carneiro, Evolutionism in Cultural Anthropology. (Westview Press, Boulder, Colorado, 2003).

5. S. K. Sanderson, Rethinking Sociological Theory: Introducing and Explaining a Scientific Theoretical Sociology. (Taylor \& Francis, 2015).

6. F. Nielsen, The ecological-evolutionary typology of human societies and the evolution of social inequality. Sociological Theory 22, 292 (Jun, 2004).

7. I. Morris, The Measure of Civilization: How Social Development Decides the Fate of Nations. (Princeton University Press, 2013).

8. A. Norenzayan et al., The Cultural evolution of Prosocial Religions. Behavioral and Brain Sciences FirstView, 1 (2014).

9. R. Boyd, P. J. Richerson, Culture and the Evolutionary Process. (Chicago University Press, 1985).

10. A. Mesoudi, Cultural Evolution: How Darwinian Theory can Explain Human Culture \& Synthesize the Social Sciences. (University of Chicago Press, London, 2011).

11. J. Henrich, The Secret of Our Success: How Culture Is Driving Human Evolution, Domesticating Our Species, and Making Us Smarter. (Princeton University Press, 2015).

12. D. J. Futuyma, Evolution. (Sinauer Associates, 2013).

13. P. Turchin, Ultrasociety: How 10,000 Years of War Made Humans the Greatest Cooperators on Earth. (2016).

14. D. C. North, Institutions, Institutional Change and Economic Performance. (Cambridge University Press, 1990).

15. F. Fukuyama, The Origins of Political Order: From Prehuman Times to the French Revolution. (Profile, 2011). 
16. P. Turchin et al., Quantitative historical analysis uncovers a single dimension of complexity that structures global variation in human social organization. Proceedings of the National Academy of Sciences 115, E144 (2018).

17. J. E. Smith et al., Leadership in Mammalian Societies: Emergence, Distribution, Power, and Payoff. Trends in Ecology \& Evolution 31, 54 (2015).

18. C. S. Spencer, Territorial expansion and primary state formation. Proceedings of the National Academy of Sciences 107, 7119 (April 20, 2010, 2010).

19. R. L. Carneiro, in The Transition to Statehood in the New World, G. D. Jones, R. R. Kautz, Eds. (Cambridge University Press, Cambridge, 1981), pp. 37-79.

20. P. Turchin, S. Gavrilets, Evolution of Complex Hierarchical Societies. Social Evolution and History 8, (2009).

21. P. Turchin, Warfare and the Evolution of Social Complexity: A Multilevel-Selection Approach. Structure and Dynamics 4, (2010).

22. H. T. Wright, Early State Dynamics as Political Experiment. Journal of Anthropological Research 62, 305 (2006).

23. P. J. Richerson, R. Boyd, in The Origin of Human Social Institutions, W. G. Runciman, Ed. (Oxford University Press, Oxford, 2001), pp. 197-234.

24. T. E. Currie et al., in Complexity and Evolution: A New Synthesis for Economics, D. S. Wilson, A. Kirkman, E. Beinhoffer, Eds. (MIT Press, Ernst Strüngmann Forum, Cambridge, 2016).

25. A. Flitton, T. E. Currie, Long-run historical and ecological determinants of economic development mediated by the cultural evolution of effective institutions. SocArxiv, (2018).

26. A. W. Johnson, T. Earle, The evolution of human societies. (Stanford University Press, Stanford, 2000).

27. J. Mayshar, O. Moav, Z. Neeman, L. Pascali, Cereals, Appropriability and Hierarchy. Centre for Economic Policy Research (2015).

28. J. C. Scott, The Art of Not Being Governed: An Anarchist History of Upland Southeast Asia. (Yale University Press, 2014).

29. K. P. Burnham, D. R. Anderson, Model Selection and Multi-Model Inference: A Practical InformationTheoretic Approach. (Springer, 2002).

30. J. Painter, A. Jeffrey, Political Geography. (SAGE Publications, 2009).

31. T. E. Currie, Agricultural productivity in past societies: Toward an empirically informed model for testing cultural evolutionary hypotheses. Cliodynamics, (2015).

32. B. John J. Wiens, The Causes Of Species Richness Patterns Across Space, Time, And Clades And The Role Of "Ecological Limits". The Quarterly Review of Biology 86, 75 (2011).

33. P. Turchin, J. M. Adams, T. D. Hall, East-West Orientation of Historical Empires and Modern States. 2015, $11(2015-08-26,2006)$.

34. E. Spolaore, R. Wacziarg, How deep are the roots of economic development? Journal of Economic Literature, forthcoming (2013).

35. T. E. Currie, S. J. Greenhill, R. D. Gray, T. Hasegawa, R. Mace, Rise and fall of political complexity in island South-East Asia and the Pacific. Nature 467, 801 (2010).

36. G. Larson et al., Current perspectives and the future of domestication studies. Proceedings of the National Academy of Sciences 111, 6139 (April 29, 2014, 2014).

37. D. Acemoglu, J. Robinson, Why Nations Fail: The Origins of Power, Prosperity, and Poverty. (Crown, New York, 2012).

38. D. McAdam, S. Tarrow, C. Tilly, Dynamics of Contention. (Cambridge University Press, 2001).

39. M. W. Diehl, Hierarchies in Action: Cui Bono? , (Center for Archaeological Investigations, Southern Illinois University, Carbondale, 2000).

40. T. E. Currie et al., Agricultural productivity in past societies: Toward an empirically informed model for testing cultural evolutionary hypotheses. Cliodynamics: The Journal of Quantitative History and Cultural Evolution 6, (2015).

41. FAO. (2012).

42. USGS. (Data available from the U.S. Geological Survey, 1993).

43. J. Pinheiro, D. Bates, S. DebRoy, D. Sarkar, R. C. Team. (R package, 2015).

44. R Core Team. (Vienna, Austria, 2015).

45. J. C. Pinheiro, D. Bates, Mixed-Effects Models in S and S-PLUS. (Springer, 2009).

46. H. Akaike, New Look at Statistical-Model Identification. Ieee Transactions on Automatic Control Ac19, 716 (1974). 
Acknowledgments: We thank Cameron Petrie for advice in constructing the map of duration of agriculture, and Joanne Wood for digitizing the empire maps. T.E.C. is supported by funding from the European Research Council (ERC) under the European Union's Horizon 2020 research and innovation programme (Grant Agreement 716212). T.E.C, and P.T. were supported in part by grants from the Tricoastal Foundation ("The Deep Roots of the Modern World: Investigating the Cultural Evolution of Economic Growth and Political Stability"), and the John Templeton Foundation ("Axial-Age Religions and the Z-Curve of Human Egalitarianism"). SG was supported in part by the National Institute for Mathematical and Biological Synthesis through NSF Award \#EF-0830858, with additional support from The University of Tennessee, Knoxville and by the US Army Research Laboratory and the US Army Research Office under grant numbers W911NF-14-1-0637, W911NF-17-1-0150. Development of the paper was facilitated by short-term visitor award to T.E.C. from the National Institute for Mathematical and Biological Synthesis (NIMBioS). 
History of agriculture and intensity of warfare shaped the evolution of large-scale human societies in Afro-Eurasia

Thomas E. Currie, Peter Turchin, \& Sergey Gavrilets

\section{Online Supplementary Information}

\section{Contents}

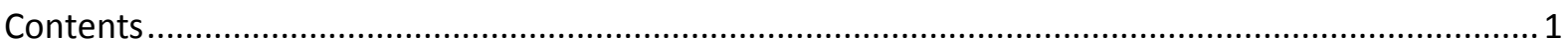

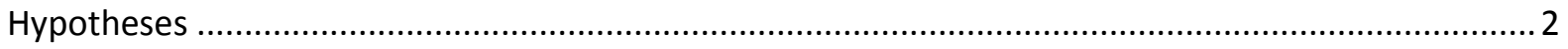

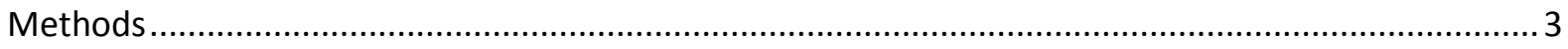

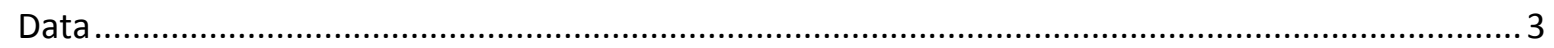

Statistical analyses

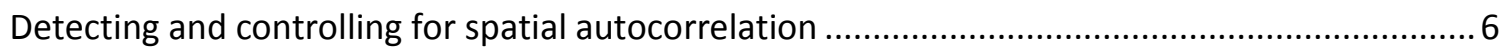

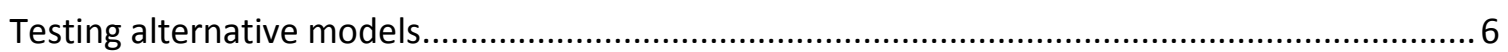

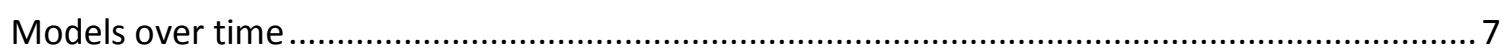

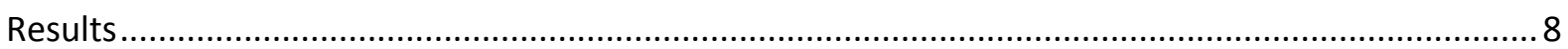

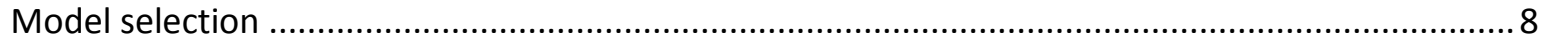

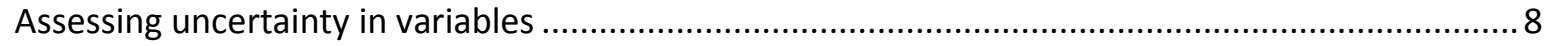

A preliminary test of the ecological and cultural similarity hypotheses......................................... 10

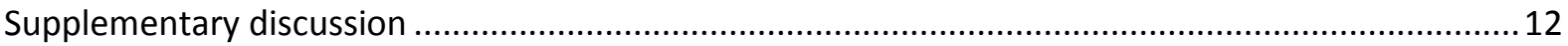

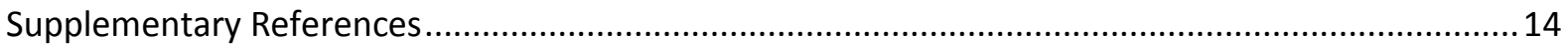




\section{Hypotheses}

In this paper we use cultural evolutionary theory to develop, organize and synthesize a number of different hypotheses about the evolution of the largest-scale societies in human history. We developed 3 primary hypotheses relating to the socio-ecological conditions that might have caused the observed patterns in the occurrence of large-scale societies over time. We also identified other factors that relate to null-hypotheses about what might explain the distribution of such societies. These different hypotheses outlined in the main text make different predictions about the relationship between imperial density and different ecological and socio-cultural variables. In table S1 we summarize the factors we examined in this paper relating to these hypotheses, the variables we use to proxy these factors, and their predicted relationships with imperial density. We also developed two further hypotheses relating to the ways in which ecological or cultural similarity may affect the spread of cultural traits supporting large-scale societies. However, these were not straightforward to incorporate into the same statistical framework and therefore dealt with separately in an exploratory fashion (see results below).

\begin{tabular}{|c|c|c|c|}
\hline \multicolumn{2}{|c|}{ Factor } & \multirow{2}{*}{$\begin{array}{l}\text { Proxy } \\
\text { Distance from the Eurasian steppe }\end{array}$} & \multirow{2}{*}{$\begin{array}{l}\text { Prediction } \\
\text { Imperial density... } \\
\text {...decreases with increasing distance } \\
\text { from the steppe }\end{array}$} \\
\hline \multirow{3}{*}{ 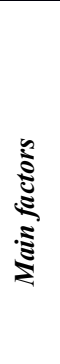 } & Warfare intensity & & \\
\hline & $\begin{array}{l}\text { Duration of } \\
\text { agriculture }\end{array}$ & Estimated time since adoption of agriculture (1) & $\begin{array}{l}\text {...increases with time since adoption } \\
\text { of agriculture }\end{array}$ \\
\hline & $\begin{array}{l}\text { Agricultural } \\
\text { productivity }\end{array}$ & $\begin{array}{l}\text { Estimated potential productivity of traditional } \\
\text { agriculture under present-day conditions (2) }\end{array}$ & $\begin{array}{l}\text {...increases with potential } \\
\text { productivity }\end{array}$ \\
\hline \multirow{2}{*}{$\frac{\sqrt{5}}{\sqrt[5]{5}}$} & Terrain & Standard deviation of altitude & ...decreases in more uneven regions \\
\hline & $\begin{array}{l}\text { Proximity to earliest } \\
\text { empires }\end{array}$ & Distance from large-scale societies at $1500 B C E$ & $\begin{array}{l}\text {...decreases with increasing distance } \\
\text { from location of first empires }\end{array}$ \\
\hline
\end{tabular}

Table S1. Potential factors important in the evolution of the largest-scale societies in human history. We identify proxy measures of these factors and outline the expected relationships with our measure of the historical duration of large-scale societies in different regions (imperial density). 


\section{Methods}

\section{Data}

Data were organized in grid cells created in ArcGIS v.10 under an equal-area projection so as to maintain a constant cell size of $10,000 \mathrm{~km}^{2}$ (approximately $100 \mathrm{~km}$ by $100 \mathrm{~km}$ ). Analyses were conducted using cells in which agriculture was practiced by $1500 \mathrm{CE}$, and cells in which potential agricultural production was possible (i.e. potential yield $>0$ ).

Imperial density: Data on the global and historical distribution of large-scale societies $\left(>100,000 \mathrm{~km}^{2}\right)$ were collated from historical atlases and related sources based on the methods outlined in Turchin et al. (3). Polygons of empires at each time step were created and areas were calculated under an equal-area projection in ArcGIS. Polygons $<100,000 \mathrm{~km}^{2}$ were not included in the final dataset. Maps of the cells inhabited by large-scale societies at each 100-year time step are shown in Fig S1. Names of polities and the map sources used to create these maps will be included in the supplementary materials accompanying the data upon publication.

Duration of agriculture: We created new maps that give an estimate of the time since agriculture was practiced in various parts of the world by assembling data. These dates were entered into ArcGIS as points and polylines (the latter were then converted to points). In order to gain full global coverage, these data were interpolated using the Spline algorithm, which creates a smooth surface that goes through the input data points. In order to incorporate uncertainty about these estimated dates, we propose a "best" estimate as well as minimum and maximum estimates (see below). Details of the sources and explanations of dates are provided as an appendix to this document (see below).

Agricultural productivity: The agricultural productivity hypothesis reflects the natural endowment of conditions conducive to productive agriculture (e.g. climate, available crops, soil) rather than achieved agricultural production that may rely on technological or cultural innovations that raise productivity (cf. (4)). Data on estimated potential crop productivities were taken from the Food and Agriculture Organization of the UN's Global Agro-Ecological Zones (FAO GAEZ) methodology v.3 (2). Different crop types were used in different regions to reflect the kinds of crops that were grown historically. We make the simplifying assumption that overall agricultural productivity can be reasonably proxied by the maximum potential yield from the main carbohydrate staple crop. Wheat (representing temperate cereals in general) was used as the main crop for Europe, North Africa, and western to central Eurasia (as far as India), rice was the main crop for East and Southeast Asia and India, Sorghum (representing tropical cereals) was used from sub-Saharan Africa, whilst the potential productivities of Yam were estimated in sub-Saharan Africa and Southeast Asia and New Guinea/Melanesia (see Fig S3). Here we use estimates from the agro-ecological suitability and productivity model which estimates crop productivity based on soil fertility, crop management input levels, water supply, and climatic conditions. In most places we use estimates based on rainfed production. However, in some important places such as the middle-East and Egypt large rivers run through arid regions in which rainfed estimates would be zero. Therefore in such regions we take the 
estimated productivity for gravity irrigation. As rice (unlike wheat) does well in water-logged soils and is commonly grown in wet fields we also take the estimated productivities for rice cultivation under gravity irrigation where this is greater than under rainfed conditions. Medium input levels were used for both rainfed and irrigated regions to hold constant the effects of labour or crop management practices on productivity. Climatic effects were based on the baseline average climatic conditions from 1961 to 1990. In some places (i.e. India, SE Asia, sub-Saharan Africa) it can be seen that more than one crop could potentially be used to estimate productivities. In these places for each cell we use the crop that had the highest estimated productivity for that cell.

Distance measures: Great Circle distances from the Steppe, and distance from the first empires were calculated in $\mathrm{R}$ using the package geosphere (Version 1.5-7).

Steppe: The steppe region was defined according to the WWF terrestrial ecoregions of the world map and includes all the contiguous regions of steppe that extend from Europe to the Far East (3). To assess the sensitivity of our assumptions about the origins of the spread of horse-based warfare we also created a more minimal steppe classification that did not extend below the Caucasus Mountains in Eastern Europe or into the Tarim Basin in Central Asia (Fig S1). We used the maximum extent of the steppe in our main analyses and explored the effect of assuming the more minimal extent in supplementary analyses (see below).

First Empires: The first empires are defined as those regions that had empires $>100,000 \mathrm{~km}^{2}$ at 1500BC.
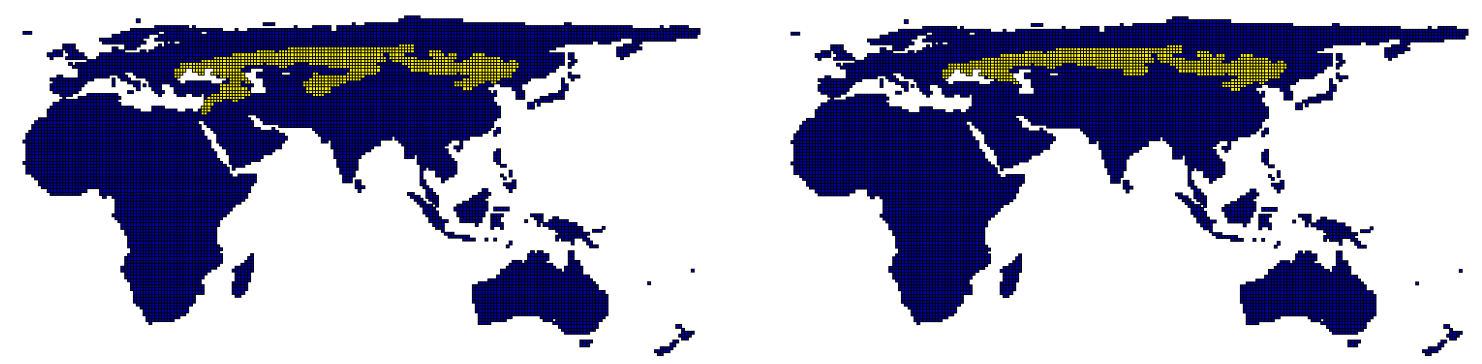

Fig. S1 Different assumptions about the extent of the Eurasian steppe used to calculate our proxy for warfare intensity (distance from the steppe). Left: Maximum extent of the steppe, Right: Minimum extent.

Elevation: Elevation data was taken from the GTOPO30 digital elevation model of the world (USGS)(resolution: 30 arc-seconds)(5). The measure of the unevenness of terrain was calculated as the standard deviation of altitude across each grid cell.

\section{Data availability}

Data, $\mathrm{R}$ code, and sources used in these analyses will be made available upon publication via the online supplementary materials. 


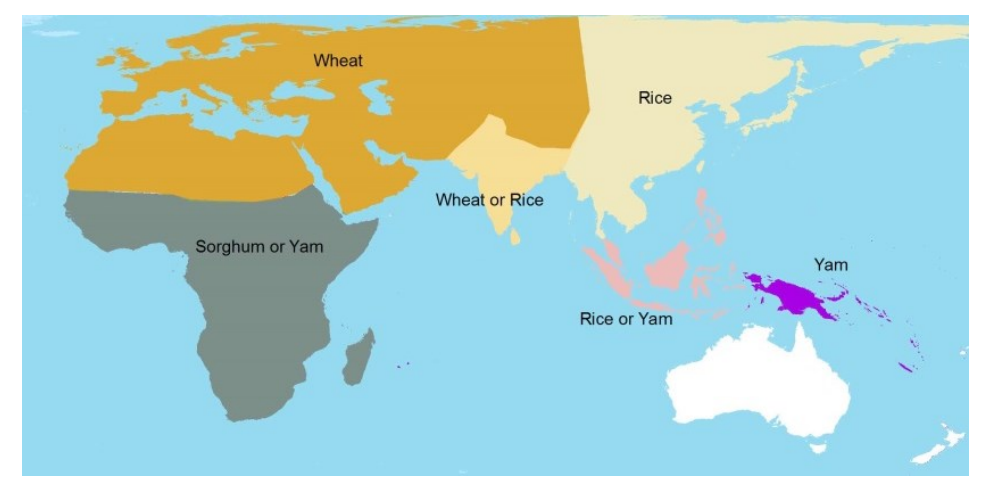

Fig S2. Distributions of main crops used to calculate potential agricultural productivity based on historical presence. In regions that have more than one candidate crop, the crop with the highest estimated productivity was used.

\section{Statistical analyses}

Main analyses were carried out using the $\mathrm{n}$ lme (non-linear mixed-effects) package (6) in $\mathrm{R}(7)$, using knowledge of longitude and latitude as random control variables (following (8)). Ordinary least squares (OLS) regression assumes that residuals are independent. Our spatially sampled grid cells may violate this assumption as points in space are not independent and may have similar values. This can lead to inaccurate parameter estimates and inflated assessments of statistical significance.

Generalized least squares (GLS) regression allows us to model the expected co-variance between our cells and control for this spatial autocorrelation in the residuals of the statistical models we specify. Whilst OLS regression can be easily run on our data, including the spatial structure of the data in nlme using GLS is extremely memory intensive, and it was not possible to run GLS on the full dataset. Given that a large number of modelling assumptions need to be tested and a large number of alternative models need to be run in order to test alternative hypotheses (see below) we ran analyses on random sub-samples of the data involving 1000 cells. For the main analyses we ran analyses over a number of such samples in order to ensure that results were not dependent on a particular sample (see below).

All dependent and predictor variables were scaled using the scale () command in $\mathrm{R}$, in order to produce standardized parameter estimates. Some variables were reflected so that all predicted relationships would be positive. 


\section{Detecting and controlling for spatial autocorrelation}

Unsurprisingly, given the gridded nature of the data, exploratory analyses indicate the presence of spatial autocorrelation in the residuals of ordinary least squares analyses. This can be demonstrated through examining the spatial relationships between the residuals of model in which distance from the steppe is regressed onto imperial density. The spatial autocorrelation between the OLS residuals can be seen in the variogram below (Fig S3), which shows that the variance in the difference between cells is lower at closer spatial distances.

Here we use the R package "nlme" to fit our GLS regression models. The package allows various spatial correlation structures to be fitted. Preliminary analyses and examination of variograms and mapped residuals indicated that the rational quadratic spatial correlation structure (corRatio) would be most appropriate, and models the correlation between two observations a distance " $d$ " apart is ( 1 $n) /\left(1+(d / r)^{2}\right)$ (where " $r$ " is the range parameter). Including a nugget effect " $n$ " appeared to substantially improve the fit of the correlation structure.

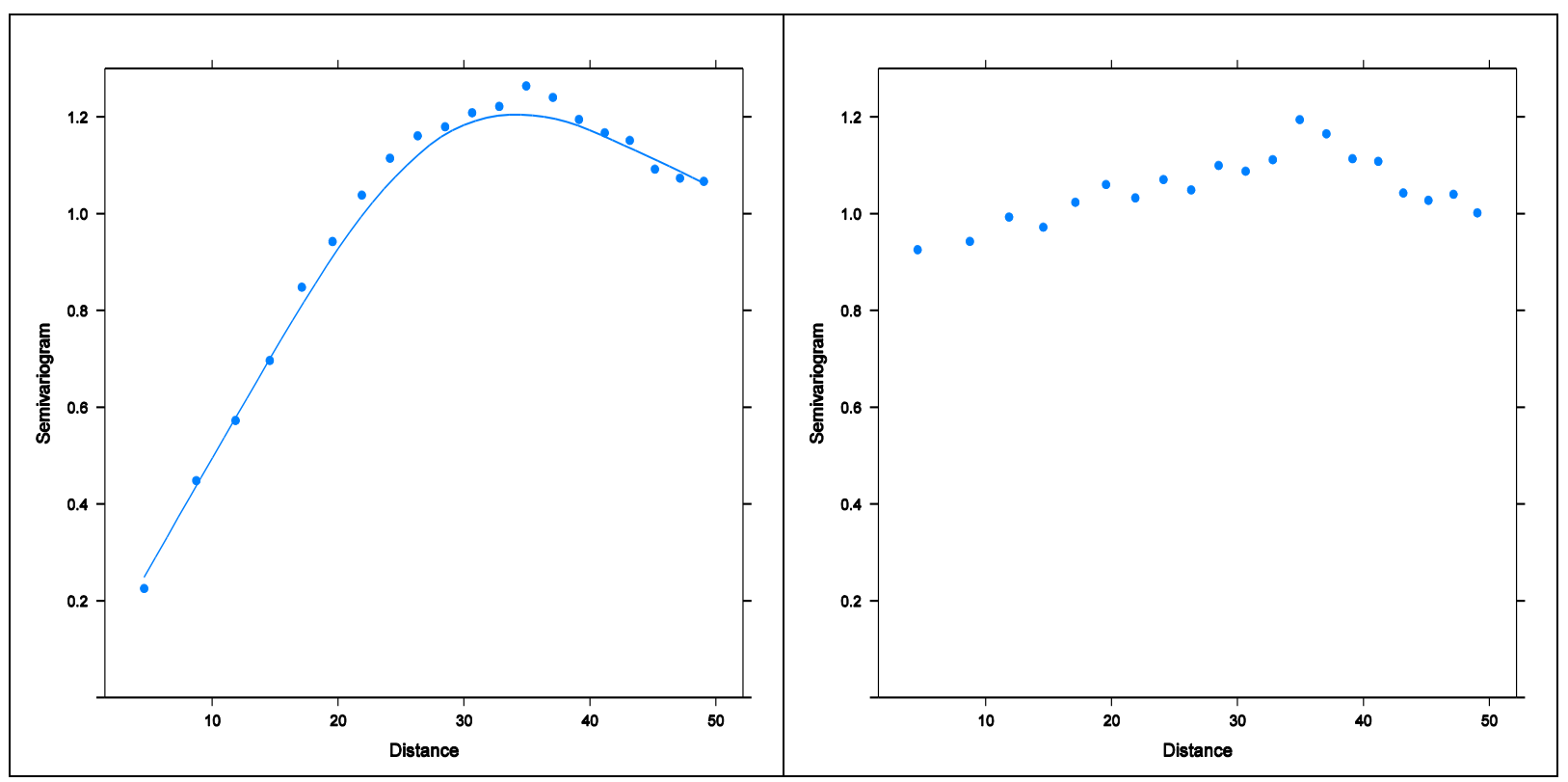

Fig S3. Semiovariograms of the residuals from an OLS model (here imperial density is regressed on distance from the steppe)(left), and the standardized residuals of a GLS model with the same variables but with longitude and latitude include as random variables to control for spatial autocorrelation (right).

\section{Testing alternative models}

In order to test between the alternative hypotheses we specified different statistical models containing different predictors of imperial density. We ran main models containing the predictor variables of 
duration of agriculture, potential productivity of agriculture, terrain ruggedness, and distance from the steppe. Running these models is computationally expensive and so such judgments need to be made for practical purposes. We also assessed to what extent model fit and parameter estimates were affected by including distance from first empires as a variable in these models.

In order to assess whether the effects of duration of agriculture and warfare intensity are amplified or inhibited by each other we included interaction terms in the main models. This allows us to see, for example, whether the effect of warfare intensity is stronger when places have been practicing agriculture for longer.

We compared different models in a model selection framework (9) based on Akaike Information Criteria (AIC)(10). The AIC is calculated as $-2 * L L H+2 k$, where LLH is the log likelihood of the model and $k$ is the number of parameters in the model.

Each model was run on 20 random samples of 1000 cells to assess variation in the parameter estimates. As likelihoods are not directly comparable across samples we use change in AIC ( $\triangle$ AIC, delta AIC) to guide model comparability across samples.

\section{Models over time}

In order to assess if there were any changes in the strength of our different main factors as predictors of imperial density over time we ran analyses over a sliding time frame of 1000 years. In other words we first analyse a model containing duration of agriculture, terrain ruggedness, productivity of agriculture, and distance from the steppe, and the interaction between duration of agriculture and distance from the steppe as predictors of imperial density for the period 1500BCE-600BCE. We then analyse the period 1400BCE-500CE etc. Within these time frames we only include areas to which agriculture had spread by the end of the time window. Each model was run on 10 random samples of 1000 cells to assess variation in the parameter estimates. 


\section{Results}

\section{Model selection}

For each of the 20 samples we calculated AIC for each of the main models, and $\Delta$ AIC for each model within that sample. Models were ranked according to their AIC (lower values indicating better fits to the data). For each sample we selected the models that were within 2 AIC units of the best-fitting model for that sample. While there was some expected variation in $\triangle \mathrm{AIC}$ and rankings between samples a consistent pattern emerged across samples. The model that included only the effects of duration of agriculture and distance from the steppe and the interaction between these two was the best-fitting in model in 13 out of 20 sub-samples. In the remaining 7 sub-samples the best-fitting model included these terms as well as standard deviation of elevation and agricultural productivity. In only one sub-sample was a model other these two within 2 AIC units of the best model (Table S2).

\begin{tabular}{|c|c|c|c|c|c|c|c|}
\hline \multirow[b]{2}{*}{ Model } & \multirow[b]{2}{*}{$\begin{array}{l}\text { mean } \\
\text { rank }\end{array}$} & \multirow[b]{2}{*}{$\begin{array}{l}\text { mean } \\
\text { delta } \\
\text { AIC }\end{array}$} & \multicolumn{5}{|c|}{$\begin{array}{c}\text { Distribution of relative likelihoods across } \\
\text { samples }\end{array}$} \\
\hline & & & Min & $25 Q$ & Med & $75 Q$ & Max \\
\hline $\mathrm{Ag}+\mathrm{St}+\mathrm{Ag} * \mathrm{St}$ & 1.35 & 0.73 & 0.05 & 0.87 & 1.00 & 1.00 & 1.00 \\
\hline $\mathrm{Ag}+\mathrm{St}+\mathrm{Ag} * \mathrm{St}+\mathrm{Y}+\mathrm{E}$ & 1.7 & 1.57 & 0.16 & 0.27 & 0.43 & 1.00 & 1.00 \\
\hline $\mathrm{Ag}+\mathrm{St}$ & 3.3 & 9.32 & 0.00 & 0.00 & 0.01 & 0.02 & 0.64 \\
\hline $\mathrm{Ag}+\mathrm{St}+\mathrm{Y}+\mathrm{E}$ & 3.65 & 10.11 & 0.00 & 0.00 & 0.01 & 0.01 & 0.13 \\
\hline $\mathrm{Ag}$ & 5.05 & 27.33 & 0.00 & 0.00 & 0.00 & 0.00 & 0.00 \\
\hline $\mathrm{St}$ & 5.95 & 39.80 & 0.00 & 0.00 & 0.00 & 0.00 & 0.00 \\
\hline Constant only & 7.5 & 62.56 & 0.00 & 0.00 & 0.00 & 0.00 & 0.00 \\
\hline $\mathrm{Y}$ & 8.15 & 62.94 & 0.00 & 0.00 & 0.00 & 0.00 & 0.00 \\
\hline $\mathrm{E}$ & 8.35 & 63.01 & 0.00 & 0.00 & 0.00 & 0.00 & 0.00 \\
\hline
\end{tabular}

$\mathrm{Ag}$ : Duration of agriculture, St: Distance from the Steppe, Y: potential productivity, E: terrain ruggedness

Table S2. Summary of fit of models across sub-samples. Within each sub-sample models were ranked according to their AIC, and differences in AIC from the best model in that sub-sample were calculated. Relative likelihoods were calculated as $\exp (-0.5 * \triangle A I C$ in that sample). The distribution of relative likelihiids is summarized as the minimum (min), maximum (max), median (Med), and $25^{\text {th }}$ (25Q) and $75^{\text {th }}$ (75Q) quartiles. Only two models $(A g+S t+A g * S t$ and $A g+S t+A g * S t+Y+E)$ are ever the best-fitting models (Max relative likelihood $=1$ )

\section{Assessing uncertainty in variables}

The construction of the variables we have used to examine to different hypotheses in this paper rest on certain assumptions and rely on the information used to construct them. As such there is a degree of uncertainty in the measurement of these variables. In order to assess whether this uncertainty affects the overall findings we created different measures for the variables of interest. 
Specifically for the variables that our main analyses revealed to be the strongest predictors of imperial density (distance from the steppe, and duration of agriculture) we created different measures based on different assumptions. For distance from the steppe we created a based on a narrower definition of the steppe that leads to two major changes: the minimal definition does not extend 1) below the Caucasus Mountains into the Middle East, 2) into the Tarim Basin in Central Asia (see Fig S1). For duration of agriculture, dates from the literature on the beginnings of agriculture in different regions are often presented as ranges. In addition to our "best" estimate we therefore also created a minimum and maximum estimate based on the information available (see below for description of each region).

As Table 1 in the main text shows these variables show very similar patterns in terms of their raw correlations with imperial density. The "best" duration of agriculture estimate shows a correlation coefficient of -0.56 , while it slightly higher for the minimum estimate (-0.61) and slightly smaller for the maximum estimate (-0.53). For distance for the steppe the correlation coefficients both measurements are identical (-0.72). However, these estimates do not take into account spatial autocorrelation, nor the effects of including other variables. We therefore ran confirmatory GLS analyses using nlme that examined combinations of the different duration of agriculture and distance from the steppe measures. The results were extremely consistent across these different parameter combinations (Table S3) demonstrating that our main findings are robust to different assumptions about the precise values of these variables.

\begin{tabular}{|r|r|r|r|r|r|r|r|}
\hline & & \multicolumn{3}{|c|}{ Duration of agriculture } & \multicolumn{2}{c|}{$\begin{array}{c}\text { Distance from the } \\
\text { Steppe }\end{array}$} & \\
\hline Model & intercept & Best & Min & Max & Min & Max & interaction \\
\hline 1 & -0.12 & 0.35 & & & 0.32 & & \\
\hline 2 & -0.09 & & 0.37 & & & 0.35 & \\
\hline 3 & -0.12 & & 0.37 & & 0.31 & & \\
\hline 4 & -0.08 & & & 0.29 & & 0.39 & \\
\hline 5 & -0.13 & & & 0.29 & 0.36 & & \\
\hline 6 & -0.19 & 0.26 & & & 0.43 & & 0.16 \\
\hline 7 & -0.16 & & 0.26 & & & 0.43 & 0.16 \\
\hline 8 & -0.19 & & 0.28 & & 0.40 & & 0.14 \\
\hline 9 & -0.14 & & & 0.24 & & 0.46 & 0.17 \\
\hline 10 & -0.19 & & & 0.23 & 0.46 & & 0.17 \\
\hline
\end{tabular}

Table S3. Confirmatory analyses examining the effect of using different measures of the duration of agriculture and distance from the steppe variables. Standardized parameter estimates are extremely similar across similar models (i.e. those with or without the interaction between the duration of agriculture and distance from the steppe variables). For comparison the parameter estimates in the main analyses were: duration of agriculture (best) $=0.25$, distance from the steppe $(\max )=0.45$, interaction $=0.16$, and duration of agriculture (best) $=$ 0.34 , distance from the steppe (max) $=0.36$ when the interaction term was not included. Analyses were run on 5 sub-samples of the data and the mean parameter estimates across these run are shown here. 


\section{A preliminary test of the ecological and cultural similarity hypotheses}

As discussed in the main manuscript, traits that enable societies to become spread over larger regions may be more likely to be transmitted between societies that are similar ecologically and culturally, or human groups may find it easier to spread and expand their control over regions that are similar ecologically or culturally. A prediction that follows from these ideas is that regions where cultural or ecological similarity extends over larger areas will be home to greater imperial density because i) the rate at which societies can acquire traits that enable larger scale societies is greater, ii) the opportunity to extend control over a larger area is greater. As a preliminary test of these predictions we systematically classify the old world into regions of ecological and cultural similarity and assess whether imperial density is greater where these are larger regions.

For the ecological similarity hypothesis, we classified ecological zones according to the zoogeographic zones identified by Holt et al. (11) based on the distributions and phylogenetic relationships of a large number of vertebrate species. These zones therefore reflect regions in which similar animal species are found. The area covered by each zoogeographic zone was calculated under an equal area projection. For the cultural similarity hypothesis, we classified cultural zones (i.e. regions of greater cultural similarity and shared cultural descent) language families, and were taken from Diamond \& Bellwood (figure 2)(12). We use language family distributions here as they thought to reflect deep cultural or demographic expansions that took place prior to the time period considered here. Societies belonging to a particular language family are thought to have descended from a shared common ancestral society and may therefore share more features in common with each other than with societies from other language families. As this is a preliminary test this map was simplified in a few ways to capture the broadest patterns of cultural similarity and to reflect the fact that the language family affiliation in some regions has changed over the course of the time span being considered here, e.g. the regions occupied in the present day by Hungarian, which is a Uralic language, and Turkish, which an Altaic language, are classified as Indo-European in our map, reflecting the relatively late arrival of these group into these regions. As with the zoogeographic zones, the area covered by each language family was calculated under an equal area projection.

Using ArcGIS we overlaid the each cultural and ecological zone on our grid map and calculated mean imperial density within each zone. The results show that there is substantial variation between ecological and cultural zones in terms of imperial density (Fig S4). However there is not an apparent and clear relationship between imperial density and the area covered by these zones. Therefore the predictions of the ecological and cultural similarity hypotheses as outlined above are not supported. The preliminary nature of these analyses should be re-emphasized and there are a number of reasons that these hypotheses are not supported. Importantly, while our categorizations of ecological and cultural zones have the advantage of being suitably coarse grain for simple tests, they may not be the most appropriate classifications for testing these ideas. For example, we have chosen a broad, simplified language family distribution that reflects the period around the end of our analysis period, yet we know that there are some issues here such as it doesn't capture variation in similarity within language families (e.g. in sub-Saharan Africa Bantu languages are more closely related to each other than they are to other branches of the Niger-Congo family (13)), New Guinea is treated as whole despite there being many language families here (14), and some classifications, like Altaic, are controversial $(15,16)$. Similarly, the ecological zones classification we used was chosen because it reflected well the logic of the original argument about latitudinal axes (17) but these could of course be drawn in different ways by making different assumptions (18). Future work will examine other means assessing these hypotheses such as examining alternative classifications based on other criteria (e.g. plant-based ecozones (19), or shared religion) or using more quantitative means of assessing 
similarity. Another way of assessing these hypotheses might be to examine more closely the connectivity between different areas that is produced by ecological or cultural similarity. This may be difficult to operationalize within the statistical framework used in this paper, but again could perhaps be tackled using computer simulations.

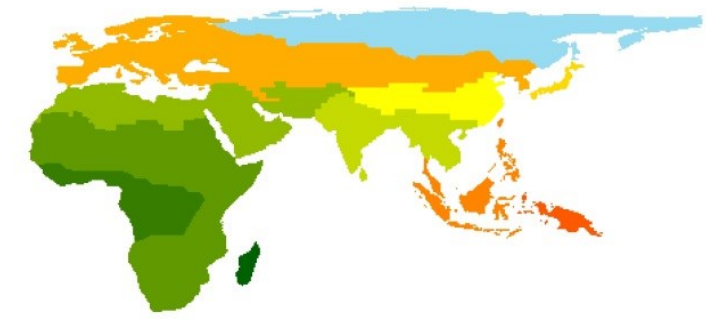

Biogeographic Zones (ecological similarity)
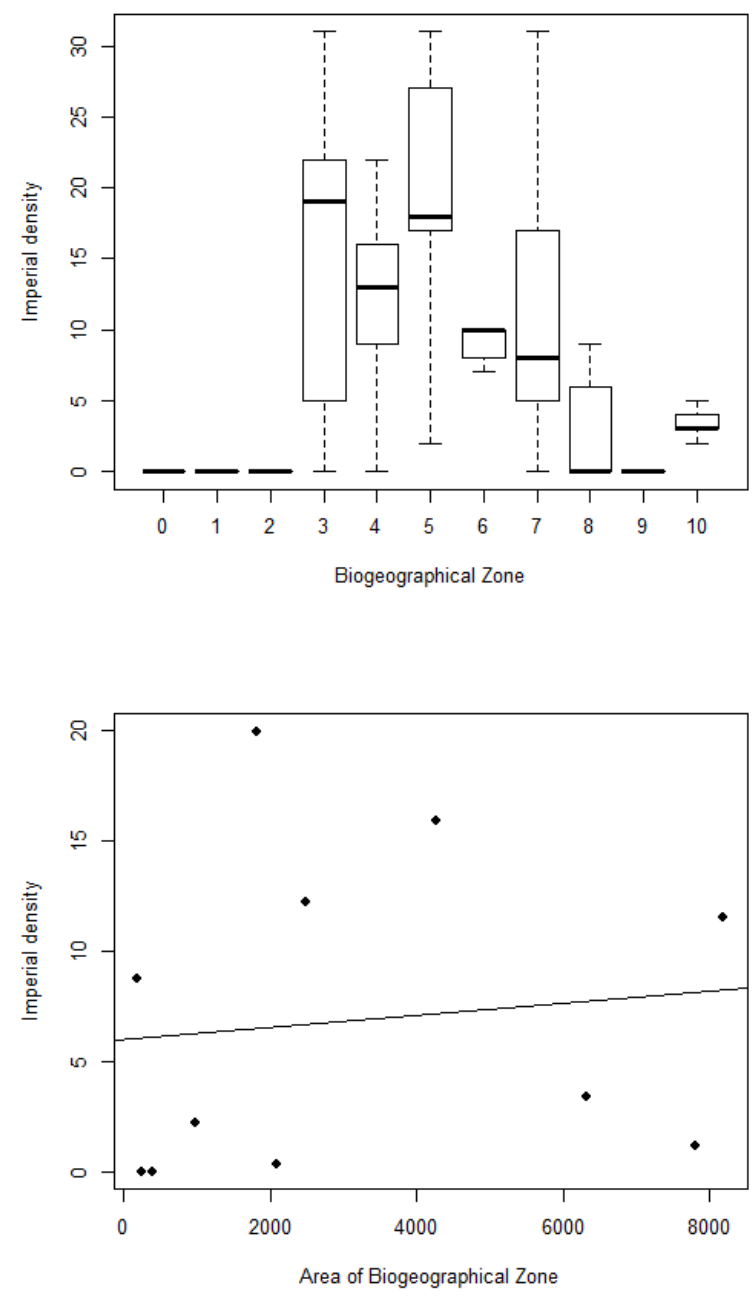

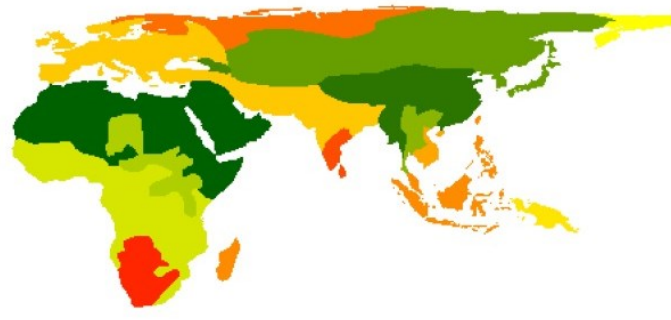

Language families (cultural similarity)
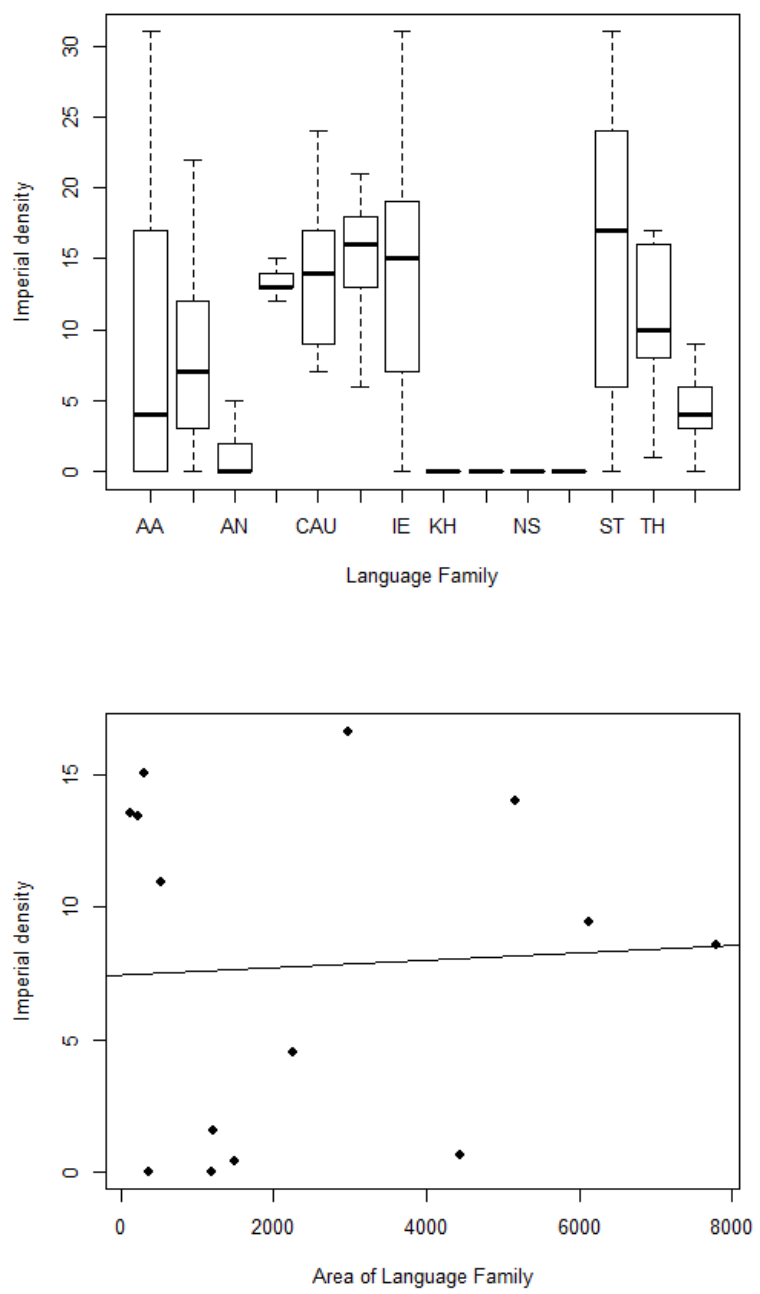

Fig S4. Geographic distribution (top) of two categorical predictor variables that are hypothesized to affect the ability of large-scale societies to form. Biogeographic zones and Language family both 
show significant differences in imperial density (middle), but in contrast to the predictions of the hypothesis the largest regions are not generally those with greatest imperial density (bottom).

\section{Supplementary discussion}

The Darwinian cultural evolutionary approach adopted in this paper helps to highlight that whilst being part of larger and more cohesive societies potentially provides benefits to individuals or groups, there are also costs associated with increased group size, including the time and energy required to communicate and coordinate actions over large distances, and the increased probability of free-riding in larger groups $(20,21)$. A particular issue is that of collective action problems which arise when individuals pay certain costs privately in order to produce a group-beneficial outcome (22). As individuals can benefit without contributing such situations provide an incentive to reduce effort or contribution to the public good. If too many individuals fail to contribute then the public good will not be produced or will be less effective and everybody will suffer (20). Cultural norms and institutions can provide solutions to such collective action problems (23-25). However, such institutions may also have their own costs. For example, members of society not involved in food production have to be supported through payment of tribute or taxes, whilst individuals established in positions of political authority can exploit their position and disproportionately benefit themselves.

In order for institutions to be favoured by selection they must on balance provided greater benefits than costs. These benefits may come from solving some ecological adaptive problem (games of "usvs-nature")(20), e.g. pooling risk of crop failure, or returns to scale in the construction of irrigation systems create direct benefits. Benefits may also be evident due to competition with other groups (games of "us-vs-them"), where being larger and more cohesive can help groups win conflicts, representing a cultural form of multilevel selection $(3,26,27)$. In this paper we have focussed on one case of us-vs-them explanations; the role of warfare intensity in providing a selective force that favoured the emergence of institutions that enabled groups to function on a massive scale. It seems unlikely that us-vs-nature explanations are plausible for the scale of society we are dealing with as solving problems of agricultural production, or ensuring access to resources typically involve smaller distances and can be solved at more local levels $(28,29)$. Although on a contemporary note the scale of certain ecological challenges we face today such as climate change or energy production may well be characterized as "games" of us-vs-nature. We also note that institutions can be established by elites that benefit themselves even at the expense of the majority of the population. It could be possible that elites sought to increase social scale in the face of hostility from other groups to protect their own interests and create situations in which they and their relatives and offspring benefited even if this was at a net cost to the rest of the population. While we cannot rule out this explanation with the current data, we note that large inequalities within societies and more extractive institutions are thought to be detrimental to overall group success for a number of reasons. First, they may not make the most of the talents of the majority of the population so may not perform as well economically and politically (30), which could lead to lower population growth or even decline as there might be fewer resources. Secondly, inequality may reduce social cohesion and make societies less effective in between group competition (31), or cause dissatisfied members of the population to leave or join other groups. In future work, we will use systematic historical data to assess between-group competition and the changing levels of inequality over time (32). 
Here we have considered that variation in the onset of agriculture has enabled larger-scale societies to develop more in some regions because they have had longer to generate the kinds of institutions that such organization requires. Socio-political organization, like other aspects of human culture, is likely to proceed in a cumulative fashion $(33,34)$, with larger-scale societies building upon and elaborating from existing norms or institutions $(35,36)$. Related to this, another way that agriculture might affect the socio-political evolution is that it created higher population densities, which is hypothesized to influence the rate at which cultural variants are created and retained within a population (37-39). However, institutions are a group-level property (40) and many may be established or imposed by ruling elites who make up a relatively small proportion of the population. Cumulative evolution of institutions may therefore be less affected by overall population size or density due to such a mechanism, although the distribution of populations in space could have important consequences for the kinds of institutions that need to be established in order to organize societies effectively. Another reason that duration of agriculture could be linked to the occurrence of large-scale societies is that the intensity of between-group competition may have been stronger in places in which groups with higher population densities were established earlier. However, this possibility is controlled for by including distance from first empires; in these confirmatory models duration of agriculture was still a substantial and reliable predictor of imperial density. Finally another consideration about the role of agriculture is that our warfare hypothesis assumes that pastoralists would be raiding agricultural regions that had a certain level of organization or productivity. In early analyses we included interactions between potential productivity and a proxy of warfare intensity, but these were not good predictors. Further tests that incorporated actual productivity and political development over time might prove insightful, although this would require careful consideration so as to avoid circular logic and spurious correlations. Such non-linear processes might be usefully assessed within a computational, agentbased modelling framework that incorporates these kinds of dynamic feedbacks $(3,41-43)$.

In this study we have assembled data from a variety of sources in order to test between various competing hypotheses. In going through this process various decisions and assumptions have to be made and it is important to recognize the limitations of the data and assess what affect these decisions might have on our findings. Our dependent variable of imperial density is made up of historical maps of the estimated extent of large societies. We have focussed only on the largest societies as these are more likely to have had their presence recorded in the archaeological and historical record, and so reduces the bias that exists in our knowledge about different parts of the world. One source of error with such data is that their course-grain nature does not allow us to distinguish between different forms of organization within these societies, or the extent to which different parts of these territories were important or directly controlled. This could create errors; for example, map territories may cover regions of high elevation or rough terrain even if those areas were peripheral to the main concerns and functions of the polity. This could explain why our elevation control variable does show a strong relationship with imperial density. However, the issue does not appear to have generated any false relationships between imperial density and our main predictor variables.

As noted above one issue with our distance from the steppe variable is that all regions bordering the steppe may not have been targets for raiding pastoralists. Large societies did not start forming in Eastern Europe until later in the time span considered possibly due to the adoption of plough technologies that increased actual agricultural productivity (3). This might explain why the strength of the distance from steppe variable increases in the later periods in our time-varying analyses. To assess 
whether this biases results we have included estimates of the spread of cavalry from historical data, however this proxy for warfare intensity performs in a similar way to the distance from steppe variable including its interaction with duration of agriculture. Another caveat that should be noted here is that this measure does not include other forms of horse-based warfare such as the use of chariots which were developed at an earlier period. So while there are sources of error in the data used in this study, as there will be in any comparative analysis, there does not appear to be reasons to suspect that these errors are due to systematic biases that may have favoured some of our main hypotheses over others. Even with these limitations it is important to attempt to systematically address hypotheses in this way, and highlight where future data collection efforts should be targeted. By going through such a process we help to uncover some of the hidden assumptions in ideas that have often only been presented as informal verbal arguments.

\section{Supplementary References}

1. M. Mazoyer, L. Roudart, $A$ history of world agriculture: from the neolithic age to the current crisis. (Earthscan/James \& James, 2006).

2. FAO. (2012).

3. P. Turchin, T. E. Currie, E. A. L. Turner, S. Gavrilets, War, space, and the evolution of Old World complex societies. Proceedings of the National Academy of Sciences 110, 16384 (October 8, 2013, 2013).

4. T. E. Currie et al., Agricultural productivity in past societies: Toward an empirically informed model for testing cultural evolutionary hypotheses. Cliodynamics: The Journal of Quantitative History and Cultural Evolution 6, (2015).

5. P. Turchin, T. E. Currie, E. Turner, Mapping the Spread of Mounted Warfare. Cliodynamics, (in press).

6. USGS. (Data available from the U.S. Geological Survey, 1993).

7. B. G. Holt et al., An Update of Wallace's Zoogeographic Regions of the World. Science 339, 74 (January 4, 2013, 2013).

8. J. Diamond, P. Bellwood, Farmers and their languages: The first expansions. Science 300, 597 (2003).

9. J. Pinheiro, D. Bates, S. DebRoy, D. Sarkar, R. C. Team. (R package, 2015).

10. R Core Team. (Vienna, Austria, 2015).

11. J. C. Pinheiro, D. Bates, Mixed-Effects Models in S and S-PLUS. (Springer, 2009).

12. K. P. Burnham, D. R. Anderson, Model Selection and Multi-Model Inference: A Practical Information-Theoretic Approach. (Springer, 2002).

13. H. Akaike, New Look at Statistical-Model Identification. leee Transactions on Automatic Control Ac19, 716 (1974).

14. T. E. Currie, R. Mace, Mode and tempo in the evolution of socio-political organization: reconciling "Darwinian" and "Spencerian" evolutionary approaches in anthropology. Philosophical Transactions of the Royal Society B: Biological Sciences 366, 1108 (April 12, 2011, 2011).

15. R. L. Carneiro, Evolutionism in Cultural Anthropology. (Westview Press, Boulder, Colorado, 2003).

16. A. Mesoudi, Cultural Evolution: How Darwinian Theory can Explain Human Culture \& Synthesize the Social Sciences. (University of Chicago Press, London, 2011).

17. S. Gavrilets, Collective action problem in heterogeneous groups. Philosophical Transactions of the Royal Society of London B: Biological Sciences 370, (2015-12-05 00:00:00, 2015). 
18. P. Turchin, in Cultural Evolution, P. J. Richerson, Morten H. Christiansen, Eds. (MIT Press, Cambridge, MA, 2013), vol. 12, pp. 61-73.

19. M. Olson, The Logic of Collective Action: Public Goods and the Theory of Groups. (Harvard University Press, Cambridge, MA, 1965).

20. P. Richerson, J. Henrich, Tribal Social Instincts and the Cultural Evolution of Institutions to Solve Collective Action Problems. Cliodynamics 3, 38 (2012).

21. T. E. Currie et al., in Complexity and Evolution: A New Synthesis for Economics, D. S. Wilson, A. Kirkman, E. Beinhoffer, Eds. (MIT Press, Ernst Strüngmann Forum, Cambridge, 2016).

22. S. T. Powers, C. P. van Schaik, L. Lehmann, How institutions shaped the last major evolutionary transition to large-scale human societies. Philosophical Transactions of the Royal Society of London B: Biological Sciences 371, (2016).

23. M. R. Zefferman, S. Mathew, An evolutionary theory of large-scale human warfare: Groupstructured cultural selection. Evolutionary Anthropology: Issues, News, and Reviews 24, 50 (2015).

24. T. E. Currie, R. Mace, Political complexity predicts the spread of ethnolinguistic groups. Proceedings of the National Academy of Sciences of the United States of America 106, 7339 (May 5, 2009).

25. T. Earle, Economic and social organization of a complex chiefdom : the Halelea District, Kauai, Hawaii. (Museum of Anthropology, University of Michigan, Ann Arbor, 1978).

26. P. V. Kirch, The Evolution of the Polynesian Chiefdoms. New Studies in Archaeology (Cambridge University Press, Cambridge, 1984).

27. D. Acemoglu, J. A. Robinson, Why Nations Fail: The Origins of Power, Proseprity, and Poverty. (Crown Publishing Group, New York, 2012).

28. P. Turchin, Historical dynamics: why states rise and fall. (Princeton University Press, Princeton, NJ, 2003).

29. P. Turchin et al., Seshat: The Global History Databank. Cliodynamics: The Journal of Quantitative History and Cultural Evolution 6, (2015).

30. M. Kempe, S. J. Lycett, A. Mesoudi, From cultural traditions to cumulative culture: parameterizing the differences between human and nonhuman culture. Journal of Theoretical Biology 359, 29 (10/21/, 2014).

31. E. A. Smith, Endless forms: human behavioural diversity and evolved universals. Philosophical Transactions of the Royal Society B: Biological Sciences 366, 325 (February 12, 2011, 2011).

32. T. E. Currie, S. J. Greenhill, R. D. Gray, T. Hasegawa, R. Mace, Rise and fall of political complexity in island South-East Asia and the Pacific. Nature 467, 801 (2010).

33. J. Henrich, Demography and cultural evolution: How adaptive cultural processes can produce maladaptive losses - The Tasmanian case. American Antiquity 69, 197 (Apr, 2004).

34. A. Powell, S. Shennan, M. G. Thomas, Late Pleistocene Demography and the Appearance of Modern Human Behavior. Science 324, 1298 (Jun 5, 2009).

35. P. E. Smaldino, P. J. Richerson, in Handbook of Human Computation, P. Michelucci, Ed.

(Springer New York, New York, NY, 2013), pp. 979-992.

36. P. E. Smaldino, The cultural evolution of emergent group-level traits. Behavioral and Brain Sciences 37, 243 (2014).

37. P. Gerbault et al., Storytelling and story testing in domestication. Proceedings of the National Academy of Sciences 111, 6159 (April 29, 2014, 2014).

38. A. Griffin, C. Stanish, An agent-based model of prehistoric settlement patterns and political consolidation in the Lake Titicaca basin of Peru and Bolivia. Structure and Dynamics 2, (2007).

39. C. Cioffi-Revilla, Introduction to Computational Social Science: Principles and Applications. (Springer London, 2013).

40. T. E. Currie, A. Meade, M. Guillon, R. Mace, Cultural phylogeography of the Bantu Languages of sub-Saharan Africa. Proceedings of the Royal Society B: Biological Sciences 280, (July 7, 2013, 2013). 
41. W. A. Foley, The languages of New Guinea. Annual Review of Anthropology 29, 357 (2000).

42. A. Vovin, Japanese, Korean, and Other 'Non-Altaic' Languages. Central Asiatic Journal 53, 105 (2009).

43. R. A. Miller, I. f. s. kulturforskning, Languages and History: Japanese, Korean, and Altaic. (Institute for Comparative Research in Human Culture, 1996).

44. J. Diamond, Guns, germs and Steel. (Vintage, London, 1997).

45. H. Kreft, W. Jetz, Comment on "An Update of Wallace's Zoogeographic Regions of the World". Science 341, 343 (2013-07-26 00:00:00, 2013).

46. D. M. Olson et al., Terrestrial ecoregions of the worlds: A new map of life on Earth. Bioscience 51, 933 (2001). 


\title{
History of agriculture and intensity of warfare shaped the evolution of large-scale human societies in Afro-Eurasia
}

\author{
Thomas E. Currie, Peter Turchin, \& Sergey Gavrilets
}

\section{APPENDIX: Creating maps of the spread of agriculture}

In order to create our duration of agriculture variables we needed spatially-explicit dates of the beginnings of agricultural production in different parts of the Old world and New Guinea. In order to do this we needed a map. However, a reliable, up-to-date map that covers the whole of our area of interest does not exist. We therefore created such a map by joining together information from different regions, assigning dates to points and lines in a GIS and interpolating between these points (see Methods above). Here we describe the sources used and the decisions made for the different regions of the world. The sources below are primarily syntheses of primary sources including some maps, but in some cases we also consulted primary sources for certain radiocarbon dates of archaeological materials. In addition to the regionally specific sources consulted below we also made use of some more general sources. Larson et al. (1) provide a recent summary of likely dates of the beginning of agriculture in different regions of the world based on knowledge of the primary literature from a number of co-authors, while Mazoyer \& Roudart (2) provide an approximate map of the spread of agriculture which was useful for assessing broad, global-scale patterns but was not used to determine to dates.

The aim here is not to provide the definitive statement on the dates of the beginnings of agriculture in different parts of the world but rather to provide a reasonable, global-scale summary of the main patterns of the spread of agricultural forms of production. In order to produce data on the scale we need for our analyses we necessarily have to make estimates and infer dates for regions that are not well covered by the archaeological and historical records. This is done systematically by interpolating between points where information has been collected or where previous scholars have placed estimates. Particular estimates or judgements can always be updated or challenged based on new evidence or different interpretations of evidence. In order to incorporate the uncertainty inherent in such an enterprise we include a "best" estimate as well as a minimum and maximum estimate. Where possible this based on ranges presented in the literature. Our resulting maps are necessarily painted with broad brush strokes, however this is suitable for the scale of the analyses we are conducting in this paper. We feel they capture the main global-scale patterns sufficiently in a manner that is not biased to providing support for the duration of agriculture hypotheses for the emergence large scalesocieties. Our best, maximum, and minimum interpolated estimates are presented below after describing the information used for each region. 


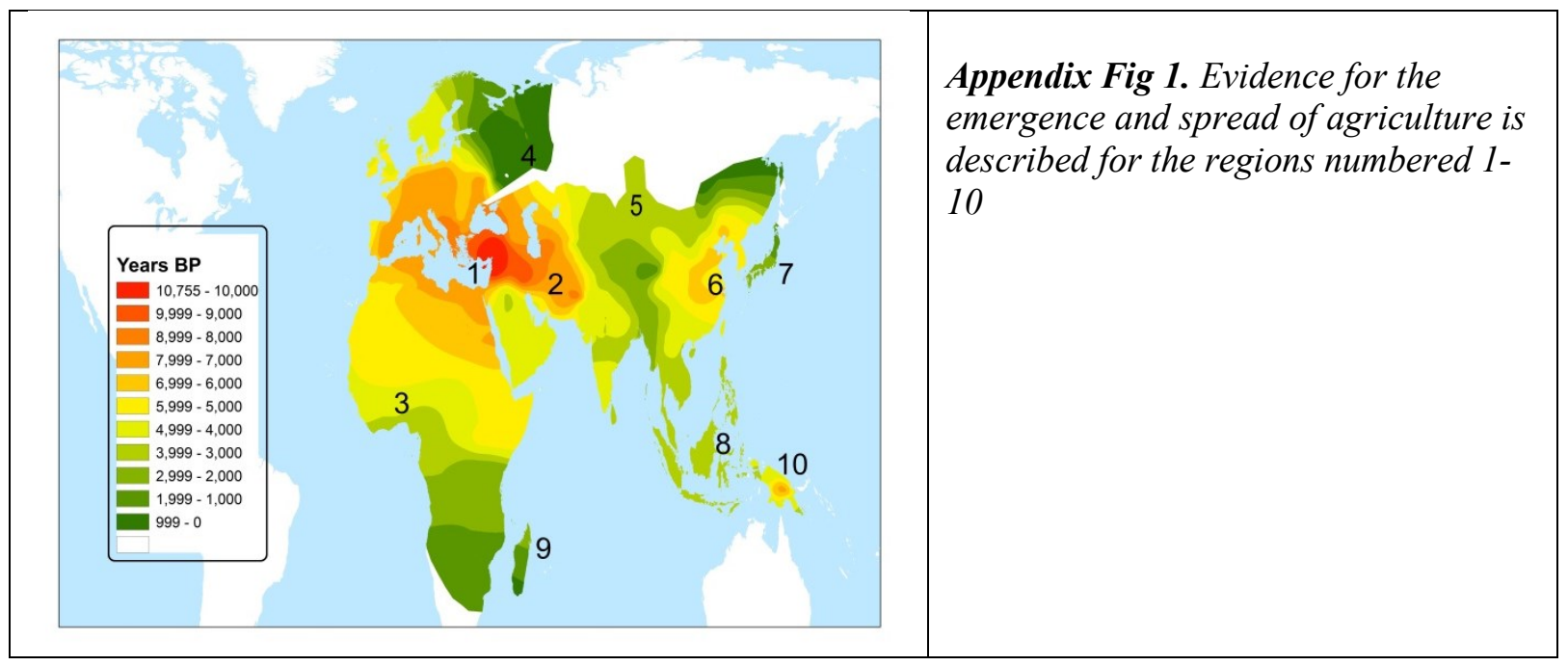

\section{SOUTHWEST ASIA, EUROPE, \& NORTH AFRIA}

Data on the spread of southwest Asian Neolithic crop assemblage were taken from Zohary et al. (3) who present a map (Plate 6, Map 2) of the earliest archaeological sites in which domesticated grain crops have been found.

\section{WEST ASIA \& SOUTH ASIA}

The eastward spread of wheat and barley (key parts of the southwest Asian Neolithic crop assemblage) through west Asia into the Indian subcontinent have been mapped by Stevens et al. (4) using the AsCAD database. For this region the timing and extent were taken from figure 2 of this publication. There is also evidence for an independent southern Indian domestication of crops, and an independent origin of rice in the Ganges - the geographical distribution of these events was incorporated using maps and information from Fuller $(5,6)$

\section{SUB-SAHARAN AFRICA}

Bellwood (7) has recently summarized archaeological and various lines of evidence for the spread of livestock with an origin in Southwest Asia into sub-Saharan Africa, the domestication of various local species of plant (names) in Sub-Saharan Africa, and the southward spread of Bantu agriculturalists from equatorial Africa (8). Fuller ( 9 ) also provides dates for earliest evidence of cattle in archaeological sites in this region.

\section{EASTERN EUROPE \& EUROPEAN RUSSIA}

The archaeological record for the spread of agriculture in this region is not as detailed as in other parts of Europe. Bellwood (7) (Figure 7.2, pg. 146) provides dates for eastern Europe - archaeological cultures Corded Ware (4800 BP in approximately modern-day Belarus, and 2500BP for regions further north) and the movement of Neolithic cultures to regions east of the Dnieper river (7200 BP). Later expansions of agriculture were assumed linked to the spread of political control and settlement by Russian principalities in the second millennium AD. Therefore, a historical atlas (http://www.worldhistorymaps.info/maps.html) was used to determine the eastern extent of the Kievan Rus principality at 1000AD. By 1300 AD this source indicates that Russian principalities had extended as far as the Urals. 


\section{NORTHERN CENTRAL ASIA}

Spengler (10) has summarized and synthesized the recent literature in this region, concluding that agriculture was present in northern Central Asia by the mid- $3^{\text {rd }}$ millennium $\mathrm{BC}$, with a later spread north into the Altai mountains.

\section{CHINA \& MAINLAND SOUTHEAST ASIA}

Recent archaeological evidence and archaeobotanical data point to two major regions of early cultivation in China: rice farming in wet fields around the Yangtze River, and dry-land cultivation of millets to the North Zhao $(11,12)$. The subsequent spread of agriculture to involving these crops to the rest of this region were estimated using figures and information derived data from geo-referenced data on archaeological sites presented in papers by Stevens et al. (4) and by Fuller and colleagues (5, 9).

\section{JAPAN}

In Japan the spread of agriculture in the form of wet-rice cultivation from Korea is associated with the beginning of the Yayoi (pre)historical period (13), and is generally considered to have begun around 2300 BP. The earliest Yayoi sites are on the island of Kyushu in western Japan. According to Kidder (14) expansion to the Kanto (around modern-day Tokyo) and Tohoku (northern) regions continued from the middle to Late Yayoi. Agriculture was practiced in northern Tohuku before the end of the Yayoi period (1700BP).

\section{ISLAND SOUTHEAST ASIA}

The spread of agriculture through island southeast Asia is associated with the spread of Austronesianspeaking societies from the island of Formosa (modern-day Taiwan)(15-17). Here this was modelled using archaeological dates from Bellwood (18), indicating a first movement into the Philippines 40004500BP, and a rapid spread to the rest of the region by around 3000-3500 BP.

\section{MADAGASCAR}

Modern populations in Madagascar speak Austronesian languages pointing to settlement from island southeast Asia as part of the expansion outlined above. Crowley (19) has summarized the evidence of human occupation: sites in northern Madagascar date to around $2000 \mathrm{BP}$, with a slightly later movement into the central highlands, and sites in the south suggest occupation was later still at around $600 \mathrm{BP}$.

\section{NEW GUINEA}

Archaeological excavations at Kuk swamp in the Highlands of New Guinea point this region as early and independent origin of agriculture, with evidence of cultivation of Taro and Yam dating to between 7000 and $4000 \mathrm{BP}(20,21)$. The timing and extent of the spread of agriculture within the island of New Guinea before Austronesians arrived on the northern coast around 3500BP (22) is unclear, however, Denham (20) argues that evidence from Banana and sugarcane in island southeast Asia suggests that there could have been contacts before 4000BP. Here we have incorporated this by modelling agriculture as spreading throughout New Guinea by 3000-5000BP. 


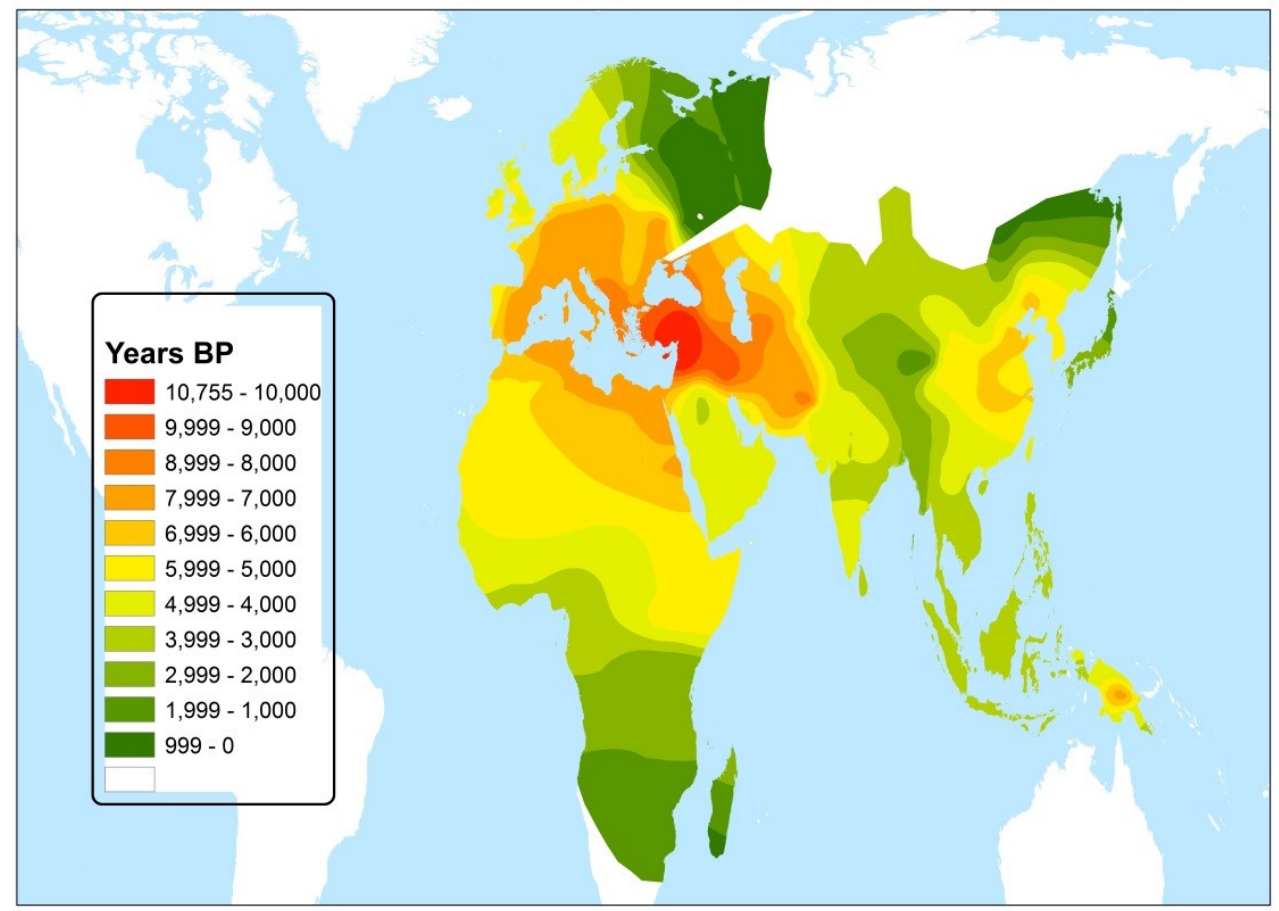

Appendix Figure 2. "Best" estimates for dates for the emergence of agriculture in Afro-Euraisa 


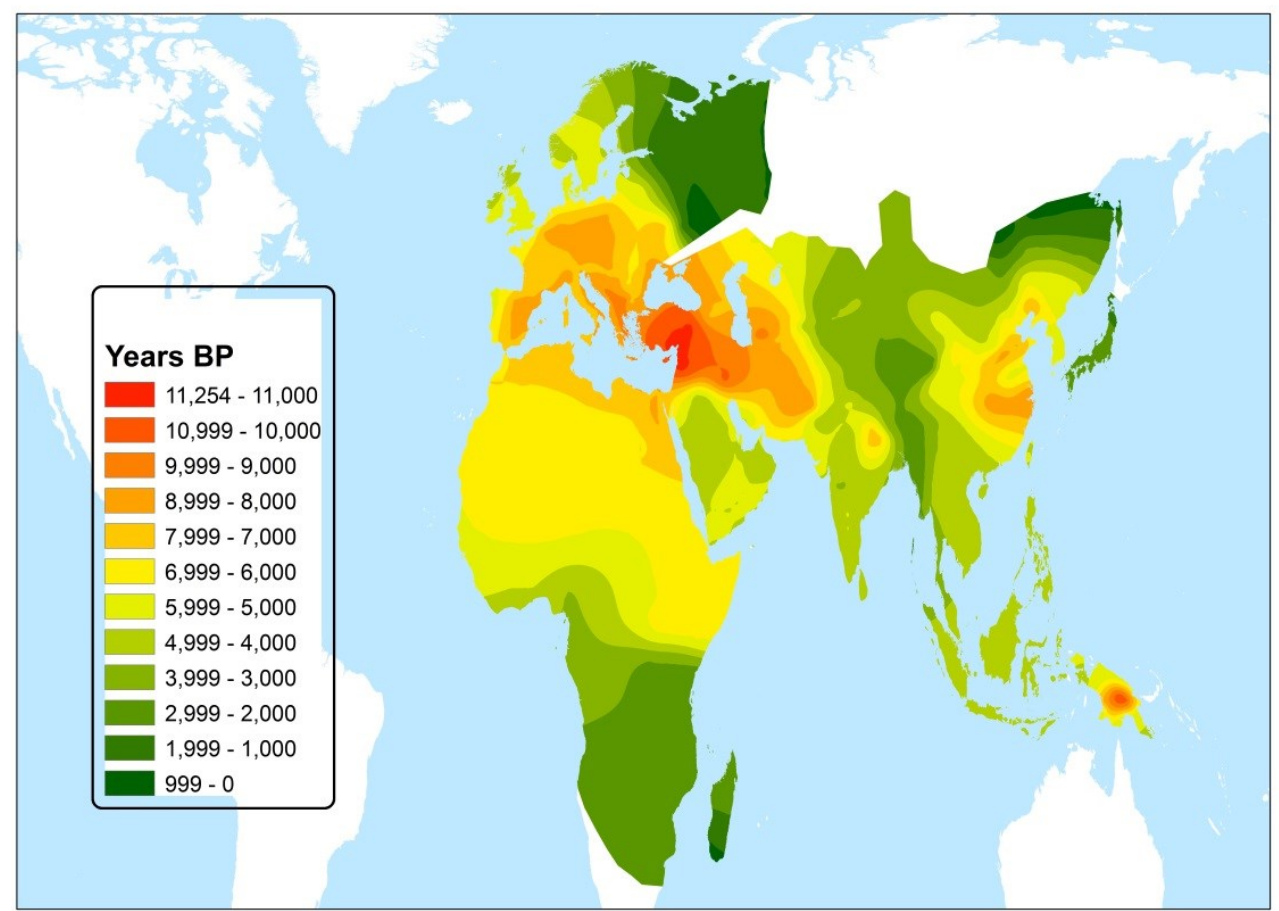

Appendix Figure 3. Maximum estimates for dates for the emergence of agriculture in Afro-Euraisa

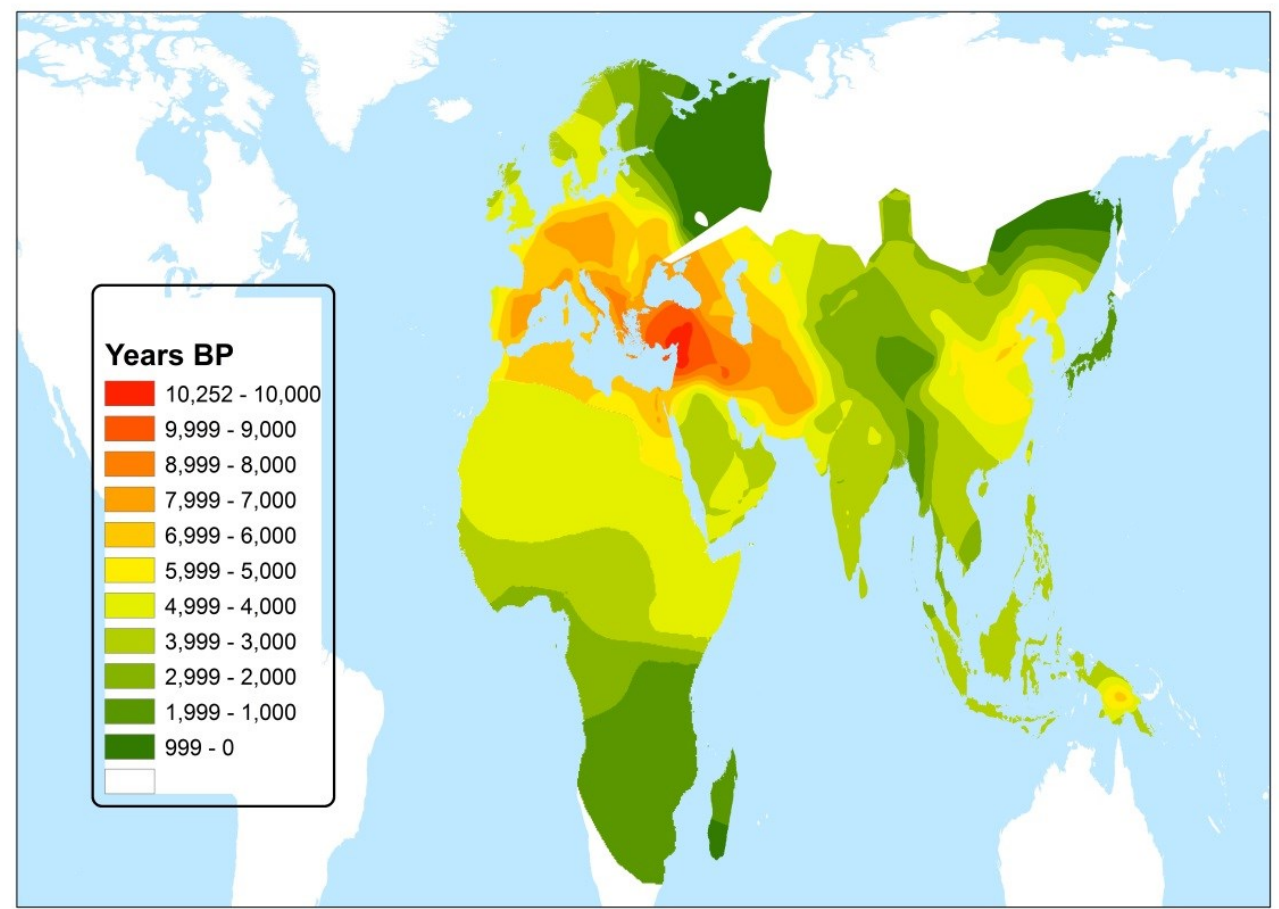

Appendix Figure 4. Minimum estimates for dates for the emergence of agriculture in Afro-Euraisa 


\section{Duration of agriculture references}

1. G. Larson et al., Current perspectives and the future of domestication studies. Proceedings of the National Academy of Sciences 111, 6139 (April 29, 2014, 2014).

2. M. Mazoyer, L. Roudart, A history of world agriculture: from the neolithic age to the current crisis. (Earthscan/James \& James, 2006).

3. D. Zohary, M. Hopf, E. Weiss, Domestication of Plants in the Old World: The Origin and Spread of Domesticated Plants in Southwest Asia, Europe, and the Mediterranean Basin. (OUP Oxford, 2012).

4. C. J. Stevens et al., Between China and South Asia: A Middle Asian corridor of crop dispersal and agricultural innovation in the Bronze Age. The Holocene 26, 1541 (2016/10/01, 2016).

5. D. Q. Fuller, Pathways to Asian Civilizations: Tracing the Origins and Spread of Rice and Rice Cultures. Rice 4, 78 (2011).

6. D. Q. Fuller, in Examining the Farming/language Dispersal Hypothesis, P. Bellwood, C. Renfrew, Eds. (McDonald Institute for Archaeological Research, University of Cambridge, Cambridge, 2002 ).

7. P. Bellwood, First Migrants: Ancient Migration in Global Perspective. (Wiley, 2014).

8. T. E. Currie, A. Meade, M. Guillon, R. Mace, Cultural phylogeography of the Bantu Languages of sub-Saharan Africa. Proceedings of the Royal Society B: Biological Sciences 280, (July 7, 2013, 2013).

9. D. Q. Fuller et al., The contribution of rice agriculture and livestock pastoralism to prehistoric methane levels. The Holocene 21, 743 (2011/08/01, 2011).

10. R. N. Spengler, N. Ryabogina, P. E. Tarasov, M. Wagner, The spread of agriculture into northern Central Asia: Timing, pathways, and environmental feedbacks. The Holocene 26, 1527 (2016/10/01, 2016).

11. Z. Zhao, New Archaeobotanic Data for the Study of the Origins of Agriculture in China. Current Anthropology 52, S295 (2011).

12. G.-A. Lee, G. W. Crawford, L. Liu, X. Chen, Plants and people from the Early Neolithic to Shang periods in North China. Proceedings of the National Academy of Sciences 104, 1087 (January 16, 2007, 2007).

13. K. Mizoguchi, The Archaeology of Japan: From the Earliest Rice Farming Villages to the Rise of the State. (Cambridge University Press, 2013).

14. J. J. E. Kidder, in The Cambridge History of Japan:, D. M. Brown, Ed. (Cambridge University Press, Cambridge, 1993), vol. 1, pp. 48-107.

15. R. D. Gray, A. J. Drummond, S. J. Greenhill, Language Phylogenies Reveal Expansion Pulses and Pauses in Pacific Settlement. Science 323, 479 (Jan 23, 2009).

16. P. Bellwood, J. J. Fox, D. Tryon, The Austronesians: Historical and Comparative Perspectives. (Australian National University, 2006).

17. P. Bellwood, Prehistory of the Indo_Malaysian Archipelago. (University of Hawai'i Press, Honolulu, 1997).

18. P. Bellwood, in Southeast Asia: from prehistory to history, I. Glover, P. Bellwood, Eds. (RoutledgeCurzon Press, NY, USA, 2004), pp. 21-40.

19. B. E. Crowley, A refined chronology of prehistoric Madagascar and the demise of the megafauna. Quaternary Science Reviews 29, 2591 (9//, 2010).

20. T. Denham, Early Agriculture and Plant Domestication in New Guinea and Island Southeast Asia. Current Anthropology 52, S379 (2011).

21. T. P. Denham et al., Origins of Agriculture at Kuk Swamp in the Highlands of New Guinea. Science 301, 189 (2003).

22. P. V. Kirch, On the Road of the Winds: An Archaeological History of the Pacific Islands before European Contact. (University of California Press, Berkeley and Los Angeles, 2000). 
